\title{
A DMP MODEL OF INTERCITY TRADE
}

\author{
Yannis M. Ioannides \\ Department of Economics, Tufts University \\ Medford, MA 02155 \\ http://sites.tufts.edu/yioannides/ $6176273294 \quad$ yannis.ioannides@tufts.edu \\ January 31, 2015
}

\begin{abstract}
The paper presents a model of an economy whose urban structure consists of cities of different types. All cities produce a non-tradeable final good using both types of tradeable intermediate varieties. Each city has an internal spatial structure: individuals commute to the CBD in order to work, when employed, and to seek jobs, when unemployed. Hiring by each intermediate producing firm is subject to frictions, which are modeled in the Diamond-Mortensen-Pissarides fashion. Job matching requires either travel to the CBD for face to face contacts or, alternatively, referrals from social contacts. City type is conferred by specialization in producing one of two types of intermediate varieties, diversified cities, where both types are produced, and there is intercity trade in intermediate varieties. The paper examines the properties of equilibrium with intercity trade and its dependence on such parameters as those pertaining to productivity, the matching process, the rate of job destruction and their consequences for unemployment, output and welfare across the economy along a steady state. The model's use of international trade tools confers a central role to labor market tightness, akin to factor intensity. A natural dependence of unemployment on city size is generated. The paper provides a framework for studying spatial mismatch. Equilibrium outcomes generically diverge from the planner's optimum: socially optimal unemployment trades off the probability of employment to search costs of firms independently for each skill type and independently of city size, and city sizes are independent of labor market tightness considerations but reflect both market size effects and the skill composition of the economy.

I acknowledge very useful comments received during presentations of very early versions of the paper at various venues, including: Conference on Research on Economic Theory and Econometrics, the North American Meetings of the Econometric Society, Search and Matching Meeting, Greater Boston Urban and Real Estate Economics Seminar, Urban Economics Association; and Southern Methodist University. I have also received useful comments by Vernon Henderson, Mark Kutzbach, Rachel Ngai, Christopher Pissarides, Theodore Papageorgiou, Ömer Özak, Frédéric Robert-Nicoud, Etienne Wasmer and Yves Zenou. I thank Philipp vom Berge for useful correspondence. All errors are mine.
\end{abstract}

JEL codes: E24, F12, F16, J60, J63, J64, R12. 


\section{Introduction}

The Great Recession of 2007-2009 and its aftermath are amply demonstrating the importance of cross-sectional aspects of business cycles. Not all parts of the US economy and not all economies of the world have been equally affected by it. The housing bubble has been most pronounced in some areas of the US, some of which experienced very dramatic declines in house prices. Some of those particular areas are currently experiencing robust recoveries, while other areas are particularly slow in recovering. Housing price dynamics is only a part of the urban and regional aspects of business cycles that happened to have attracted considerable attention recently. Equally interesting is the variation of employment dynamics over the business cycle across federated states, regions and cities in large economies. The present paper aims specifically at a better understanding urban business cycles.

Macroeconomics studies economic fluctuations by means of descriptions of the entire economy and of its decomposition in terms of different sectors. These aggregative approaches have served macroeconomics quite well, when interest is in the performance of the economy as whole. An economy's urban structure, on the other hand, allows for a glimpse into the working of the economy that allows for spatial detail. An urban perspective is made possible by a synthesis here of new economic geography and urban economics, on one hand, with the economics of markets with frictions, commonly known as the DMP model, on the other.

Unemployment in each city expresses intra-city forces as well as inter-city ones, which are different depending upon the economy's urban structure. Different cities interact via intercity trade and intercity migration, and the macroeconomic dynamics of urban business cycles reflect both those forces. Specialized cities, exemplified by the proverbial company town, may react differently to economy-wide shocks than diversified ones, exemplified by the large cities that accommodate many industries and activities. Cities that provide services to the international economy are affected differently by the national and international business

cycle than large diversified regional centers. Equilibrium modeling of cities lends additional discipline to analyses of urban unemployment and provides a systematic way of exploiting Beveridge curves, as well.

\subsection{Review of the Literature}

Business cycle phenomena, broadly speaking, that have been addressed in urban contexts involve primarily measures of employment fluctuations. Taking cues from Helsley and Strange (1990), who have an explicit urban setting in mind, Gan and Li (2004) and Zhang (2007) model job matching in specific urban settings and use it empirically to explain cyclicality in 
urban unemployment. In broadly related research that emphasizes unemployment, Gan and Zhang (2006) link city size to matching. Their model predicts that larger city sizes imply lower peak and mean unemployment rates and shorter unemployment cycles. They confirm these predictions using data for 295 US PMSAs over 1981-1997: an increase of two standard deviations in city size shortens the unemployment cycles by about 0.72 months, lowers the peak unemployment rates by 0.33 percentage points, and lowers the mean unemployment rates by 0.16 percentage points. Simon (1988) argues that the short-run immobility of labor among city labor markets contributes to frictional unemployment. The more industrially diversified a city is the lower its frictional unemployment. Using data on 91 large US SMSAs for 1977-1981 and ranking them in terms of the Herfindahl index of industrial composition of their employments, Simon finds that the twenty least and the twenty most diversified cities have frictional unemployment, respectively, 1.4 points above and 1 point below the mean. Simon (1988) and Diamond and Simon (1990) do not model the urban economy as such.

Coulson (2006) examines the broad dynamic cyclical properties of urban employment fluctuations purely empirically by means of ad hoc models. As a national economy experiences business cycle fluctuations, not all of its urban or regional sub-economies rise and fall in concert. US regions, states, and metropolitan areas rise and fall at different times and with different frequencies and intensities, and for different reasons. Unique characteristics of employment fluctuations of different cities are clearly related to the industrial composition of their employment. Coulson points to a comparison of the following three MSAs, Los Angeles, CA, Detroit, MI, and San Jose, CA over the period 1956-2002 [ibid., Figure 1]. While all three of those areas have employments that are trending upward over time during that period, the rate at which their employments do so certainly varies across cities and over time within cities. High persistence in metro unemployment rates is also documented by Kline and Moretti (2013), who develop a simple model of local labor markets and use it to studying the effects of place-based policies in the form of local job creation programs.

Owyang, Piger, Wall and Wheeler (2008) documents how important it is to look separately at high-growth and low-growth episodes. Interestingly, commonly used explanatory variables in urban economics, like human capital, industry mix, and average firm size are particularly important in explaining high-growth episodes. In contrast, low-growth is mostly related to the relative importance of manufacturing, but in ways that differ across cities. As they put it, happy cities are alike, and unhappy ones are so because of different reasons. Glaeser and Gyourko (2005) have emphasized that urban growth and decay are not, empirically speaking, two sides of the same dynamic process.

Owyang, Piger and Wall (2010) examine patterns in expansion and contraction episodes across US cities. They seek to distinguish the role of national, regional, city and industry 
effects by regressing a concordance index against an industry similarity index, which is equal to 1 when the respective cities have identical employment shares in all industries, and a number of geographic indicators including whether the principal cities in the respective metro areas are in the same state, or one metro is in the same state as the secondary city of the other, whether they lie in the same region or are contiguous, while accounting for city specific idiosyncratic effects. They find that industrial similarities do not explain patterns in the geographic similarity across cities, although they do explain the employment cycles of their particular cities. Most interestingly, they also find that cities within the same state and perhaps the same region tend to have similar employment cycles. They find that similarity in human capital and in mean establishment size are related to business cycle similarity, as measured by concordance.

The finding of poor performance of industrial similarity in explaining concordance but better performance of human capital similarity suggest that functional rather than sectoral specialization may be more important in business cycle context. Specifically, Duranton and Puga (2005) draw attention to the fact that sectoral specialization within manufacturing has declined from 1977 to 1997 in US cities, as measured by the Gini coefficient of employment. Duranton and Puga show that functional specialization of cities in favor of management and services versus production has been increasing. They report, Table 1, ibid., p. 344, increasing functional specialization as measured by the difference in the ratio of the number of executives and managers to those of production workers (employed in precision production, fabrication or assembly) between cities classified by size and the national average. Increasing differences persisted for larger cities from 1950 to 1990, while they diminished for smaller cities. These authors point to considerable additional evidence in favor of pronounced shifts from sectoral to functional urban specialization in the US as well as other economies. In agreement with the notion that functional specialization is increasing are findings by Simon (2004). He reports dramatic shifts in the distribution of employment, with industries that use skill intensively being particularly sensitive to local human capital, measured as percent of college graduates in the city as well as other measures.

Two recent papers stand out. Rappaport (2012) works with a variety of data sources using three possible explanations: one, skill mismatch of workers in high unemployment metro areas with the hiring needs of firms elsewhere; two, some metro areas offer intrinsic characteristics that make households and firms unwilling to move; three, high moving costs support long term divergence in metro unemployment areas. Rappaport's empirical analysis supports all three explanations. Metro workforce characteristics are able to account for the largest share of the variation in metro unemployment rates, when measured over complete business cycles. Characteristics more intrinsic to metro areas themselves account for 
much of this variation as well, though not as much as workforce characteristics. Estimated moving costs are sufficiently high to some households unwilling to move away from highunemployment metros. Proulx (2013) using a number of empirical tools finds that estimates for Okun's laws for MSAs show moderate to high cross-sectional dependence, a result which is robust to a number of different spatial proximity measures. In fact, the cross-sectional dependence appears to increase if instead of distance-based economic similarity-based measures are used. Decomposing the total effect of changes in the growth rate of real MSA GDP on the unemployment rate shows that the indirect effect of growth in GDP in neighboring cities dominates the direct effect of growth in local GDP.

I turn next to the recent international trade literature that emphasizes labor market flexibility as a source of comparative advantage. Cuñat and Melitz (2012), Helpman and Itskhoki (2010) and Tang (2012) introduce fluctuations in productivity. Flexibility is introduced by assuming that all allocations take place after the realization of uncertainty; rigidity is assumed to take the form of hiring decisions prior to the resolution of uncertainty. The attractiveness of the Cuñat and Melitz (2007) model lies in the fact that the advantage of flexibility versus rigidity can be expressed simply enough so that the workhorse model of Ricardian comparative advantage of Dornbusch et al. (1977) may still be utilized. That is, whether one or two factors are used in production, one can define a productivity advantage of each, where industries are ranked in terms of volatility (at the firm-level), or in terms of volatility and capital intensity of production, respectively. The model predicts that other things being equal, countries with more flexible labor markets specialize in sectors where the ability to adapt is most important, that is those affected by higher-variance shocks.

The Cuñat and Melitz (2012) theory can inform trade policy. A rigid economy may improve welfare by liberalizing trade and "import flexibility" from more flexible trade partners. Outsourcing may be simply an economy's high-volatility industries availing themselves of the comparative advantage of more flexible labor markets elsewhere. This may provide a lesson for cities in integrated economies, federal ones, like US and Canada, or like the European Union, where there are differences in mobility across cities. Helpman and Itskhoski (2010) address questions broadly related to those of Cuñat and Melitz (2012), except that their models also allow for unemployment. That is, one of the two sectors in their model produces a final good by means of a range of differentiated products, which are themselves produced with raw labor and whose production is subject to market frictions (as modeled in the DMP fashion). Trade integration benefits both countries but may raise their rates of unemployment. Unemployment may be higher or lower in the more flexible country, which has both higher total factor productivity and a lower price level. Dutt, Mitra, and Ranjan (2009) develop a simple model of international trade with search induced unemployment 
and show empirically that trade liberalization increases unemployment in the short run but reduces it in the long run, as economies adjust to a new steady state. Antràs and Costinot (2010) integrate a matching model with a general equilibrium model of trade to examine trade intermediation. They find that intermediation always magnifies the gains from trade when it allows traders from geographically separated markets to exchange their goods in integrated Walrasian markets.

Anderson, Burgess and Lane (2007) report that thicker urban labor markets are associated with more assortative matching in terms of worker and firm quality and that production complementarity and assortative matching is an important source of the urban productivity premium. Bleakley and Lin (2007) confirm these findings with US Census microdata. Centralized matching of unemployed workers with vacancies may be considered as a proxy for social connections, in the close physical proximity afforded by urban living, in the functioning of urban labor markets. ${ }^{1}$ Research by Krugman (1990) and Overman and Puga (2010) ${ }^{2}$ has considered how firms benefit from proximity to other firms because of risk pooling, which reduces hiring costs and mitigates wage and input price fluctuations. Such proximity is also beneficial in promoting entrepreneurship. However, proximity is costly in terms of congestion.

While US Census regions and US states are well described in terms of macroeconomic data series, the economies of US cities are less so and this has hampered a deeper understanding of urban business cycles. A recent and very welcome addition is GDP data by US MSAs, available annually from the US Bureau of Economic Analysis for years since 2001 for 363 Metropolitan statistical areas. A recent compilation shows that even as growth in real U.S. GDP by metropolitan area slowed from 2.0 percent in 2007 to 0.8 percent in the first quarter of 2008, the distribution of growth in real U.S. GDP by metropolitan area varies from impressive growth in some areas, as in Grand Junction, CO at 12.3 per cent, to sharp decline, as in Kokomo, IN at 10 per cent. ${ }^{3}$ BLS data on unemployment by MSA are available in monthly detail since 2000 .

An alternative approach to microfoundations of urban business cycles could be to start from the system-of-cities model [Henderson (1974)], as recently adapted by Rossi-Hansberg and Wright (2007) to the study of urban growth; see also Ioannides (2013), ch. 9. That model can account for employment fluctuations, that are generated by total factor productivity shocks, as it is standard in real business cycle models. It does not address unemployment as such, nor does it exploit the body of knowledge that has clarified numerous aspects of unemployment along the lines of the DMP approach. The DMP approach to unemployment as well as all other aspects of changes in employment and labor force status has been particularly fruitful in understanding individuals' experiences through episodes of employment, 
underemployment, and out-of-the-labor force. ${ }^{4}$ Wasmer and Zenou (2006) and Zenou 2009a) have provided a bridge between urban economics and the DMP approach. Ioannides (2013), and in particular chapters 7 and 9, builds further along those lines.

The present paper emphasizes city specialization and intercity trade allowing for richness that is unmatched by other models, including how the prospect of unemployment affects urban structure under different settings for job matching. At the same time, it is not a trivial task to determine city types in the sense of the paper empirically, because even the largest relative employment shares for industrial sectors in US cities are rather small in absolute terms. Specifically, among US cities, at least $65 \%$ of local labor forces are employed in non-traded good activities [Black and Henderson (2003)]. Therefore, the employment shares that suggest specialization must be treated cautiously. Bergsman et al. (1972) and Henderson (1988) classify cities by type, using cluster analysis with employment data from around 1970, and find very strong "typing" by manufacturing activity. Black and Henderson (2003) report that the manufacturing share has declined since then, from over $28 \%$ of US non-governmental employment to under 19\%, with many cities losing their manufacturing bases. The most recent literature has sought to elaborate on the nature of specialization, especially during an era of cities in transition as they are being transformed by churning and rapid relocation of industries across cities [Duranton (2007)]. Black and Henderson find a strong correlation between changes in city size and changes in industrial composition over 1980-1990, with both the relatively fastest and slowest growing cities experiencing the greatest change in their industrial composition. This suggests that cities change sizes because they change types. Duranton (2007) emphasizes that industries change their locations across cities rapidly, but such changes cause rather slow movements in cities' positions up and down the urban hierarchy.

This paper is not the first to think of US metropolitan areas as subeconomies for the purpose of macroeconomic analysis. Some of the earlier contributions to the literature on macroeconomics with frictions address the properties that the literature associates with effects of cities. As an example, Hall (1989) in the discussion of Blanchard and Diamond (1989) wonders whether a finding of constant returns to scale for the matching function, which in the case of Blanchard and Diamond (1989) is essentially an empirical result, would imply that active, dense labor markets "generate the same flow of matches, per given combination of unemployment and vacancies as do lower-density, smaller markets." Hall argues that the finding should be taken to imply a much higher level of specialization in the large dense markets, or else there would be no efficiency benefits from large dense markets. If specialization were not omitted then a given combination of unemployment and vacancies would generate "moderate matching rates for highly specialized workers rather then very 
rapid matching for the less specialized workers and jobs. ${ }^{5}$

More recently, Shimer (2007) studies the process of labor market adjustment when numbers of workers and vacancies are typically mismatched by defining as different the markets for all well-defined occupations in each metropolitan area. So, in Shimer's calculation, with 134 million workers in 2000 in the US who are allocated in 362 different metropolitan areas (regions with at least one urbanized area with with population 50,000 or more) and 560 micropolitan areas (regions with an urban area with population 10,000 to 50,000) and 800 different occupations, there were $922 \times 800 \approx 740,000$ "markets." His Proposition 4, ibid., p. 1082, determines uniquely the number of workers, $M$, and jobs per market, $N$; given the national unemployment and vacancy rates at $5.4 \%$ and $2.3 \%$, respectively, those numbers are $M=244.2$ and $N=236.3$, respectively. Therefore, this estimate implies 134 million / $244.2 \approx 550,000$ labor markets, which is indeed in the same range as the 740,000 number. A particularly interesting result, reported by Shimer, is that the theoretically predicted job finding rate varies with the vacancy-unemployment ratio in ways which imply a matching function that is Cobb-Douglas in vacancies and unemployment. ${ }^{6}$

The present paper adopts a DMP approach, really following Pissarides (2000), embedded in a system-of-cities model, as adapted by Fujita, Krugman and Venables (1999). It aims at accommodating the increasing mainly empirical literature on urban macroeconomics (a term due to Esteban Rossi-Hansberg). Cities may be specialized or diversified in terms of different ranges of differentiated intermediate varieties, but the present paper works primarily with specialized cities. The intermediate varieties are tradeable. Each variety is produced by a single firm, which uses labor as its only input. There are two types of varieties, $\alpha-$ and $\beta$-varieties, with each being produced by a correspondingly different kind of labor. The groups of firms producing the respective varieties make up the $\alpha-$ and $\beta$-industries. Cities specialize by producing either type of varieties, provided they host the appropriate kind of labor. Cities are diversified if they host both types of labor and thus may produce both types of varieties.

The labor market for each type of labor is subject to frictions, which are modeled in the standard Mortensen-Pissarides fashion. For simplicity I assume that jobs are destroyed at constant rates for each type of labor, and that forces individuals and firms back to the labor market. Matching of workers and vacancies is city-specific as well as industry-specific. The two ranges of varieties are combined by means of a Cobb-Douglas production function to produce in each city a final consumption good, which is not tradeable. Individuals maximize expected utility of consumption. Individuals need to travel to the central business district of the city where they reside in order work, when employed, and to be matched, when unemployed. ${ }^{7}$ However, proximity is costly in terms of congestion, which in turn generates a 
land rent gradient. Locations nearer the city center are more attractive, but land rents adjust so as identical individuals be indifferent as to where they locate. The paper also examines matching via referrals from social contacts. There are many ways in which the model can be extended. One is to go beyond the steady state analysis of the present version and model the dynamics in greater detail. In particular, it would be interesting to allow for intercity moves that follow city-specific shocks and thus allow linkages between the housing and labor markets and also introduce financial frictions. The model of intercity trade in this paper in accommodating labor market frictions highlights the role of labor market tightness in intercity resource allocation that serves as a counterpart of factor intensities in conventional international trade models. A comparison between equilibrium allocations and those of a planner's problem conclude the paper.

\section{A Model of Intercity Trade}

I develop first a model of intercity trade. ${ }^{8}$ In contrast to the model of Ioannides (2013), Section 7.8, which assumes that a tradeable final good is produced using raw labor and tradable intermediates, with only the labor market for raw labor being subject to frictions, here I follow Ziesemer (2003) and assume a dynamic monopolistic competition model for each of the industries producing the $\alpha$ - and $\beta$-varieties. Unlike Ziesemer's, the present model has two trading sectors and is applied to an intercity trade context. Broadly related approaches by Lentz and Mortensen (2012), which assumes a perfectly competitive model with product varieties and hiring with frictions by heterogeneous firms and by vom Berge (2011) do not model intercity trade. In addition to centralized search at the CBD, the paper allows for decentralized search, where workers may get referrals to job openings from their

social contacts. Such modes of search may coexist with centralized search and impact on the cities' spatial structure.

Each city produces a final good, which is neither tradeable nor storable and is consumed locally, using two composite intermediate goods, each of which are produced by combining the $\alpha$ - and $\beta$-varieties by means of CES production functions that exhibit constant returns to scale in the standard fashion of the new economic geography literature. The respective ranges are endogenous and denoted by $m_{\alpha}, m_{\beta}$, respectively. Cities may specialize in the production either of the $\alpha$ - or of the $\beta$-range of varieties; $n_{\alpha}, n_{\beta}$ denote the number of cities, respectively. This standard Dixit-Stiglitz-Krugman feature of the model gives rise to economies of scale for each urban economy.

Each city contains many competitive firms in the final goods sector which combine the 
two composite intermediates to produce a final good according a Cobb-Douglas production function. That is, output of the final good per unit of time is:

$$
Y=\left[\left(\sum_{n=1}^{n_{\alpha}} \sum_{m=1}^{m_{\alpha}} z_{\alpha_{n m}}^{1-\frac{1}{\sigma}}\right)^{\frac{\sigma}{\sigma-1}}\right]^{\phi}\left[\left(\sum_{n=1}^{n_{\beta}} \sum_{m=1}^{m_{\beta}} z_{\beta_{n m}}^{1-\frac{1}{\sigma}}\right)^{\frac{\sigma}{\sigma-1}}\right]^{1-\phi}, 0<\phi<1,1<\sigma
$$

where $z_{\alpha_{n m}}$ and $z_{\beta_{n m}}$ denote the demand by a firm in a city that produces the $\alpha$-composite and $\beta$-composite good, respectively, for an $\alpha$-variety from the range $m=1, \ldots, m_{\alpha}$, produced in city $n=1, \ldots, n_{\alpha}$, and for an $\beta$-variety from the range $m=1, \ldots, m_{\beta}$, produced in city $n=1, \ldots, n_{\beta}$. Since the marginal product of any variety tends to infinity as its quantity tends to zero, all available varieties in the economy will be used. Using symmetry for each city that produces $m_{\alpha} \alpha$-varieties, and respectively $m_{\beta} \beta$-varieties, relative to all other cities in (1), yields the simplified expression:

$$
\begin{gathered}
Y_{\alpha}=\left[\left(m_{\alpha} z_{\alpha, \alpha}^{1-\frac{1}{\sigma}}+m_{\alpha}\left(n_{\alpha}-1\right) z_{\alpha,-\alpha}^{1-\frac{1}{\sigma}}\right)^{\frac{\sigma}{\sigma-1}}\right]^{\phi}\left(n_{\beta} m_{\beta}\right)^{(1-\phi) \frac{\sigma}{\sigma-1}}\left[z_{\beta, \alpha}\right]^{1-\phi}, \\
Y_{\beta}=\left(n_{\alpha} m_{\alpha}\right)^{\phi \frac{\sigma}{\sigma-1}}\left[z_{\alpha, \beta}\right]^{\phi}\left[\left(m_{\beta} z_{\beta, \beta}^{1-\frac{1}{\sigma}}+\left(n_{\beta}-1\right) m_{\beta} z_{\beta,-\beta}^{1-\frac{1}{\sigma}}\right)^{\frac{\sigma}{\sigma-1}}\right]^{1-\phi}
\end{gathered}
$$

where $z_{\alpha, \alpha}, z_{\beta, \alpha}$ are the quantities of an intermediate variety $\alpha, \beta$ demanded by, respectively, the $\alpha$ composite industry in a city of type $\alpha$, and correspondingly $z_{\alpha, \beta}, z_{\beta, \beta}$ in a city of type $\beta$, and $z_{\alpha,-\alpha}, z_{\beta,-\beta}$, the quantities of an intermediate variety $\alpha, \beta$, respectively, demanded by an $\alpha, \beta$ city from another city of its own type, of which there exist $n_{\alpha}-1, n_{\beta}-1$. Separate accounting for imported varieties is necessary in order to be able to account for shipping costs. $^{9}$

Firms in the differentiated goods industry $j, j=\alpha, \beta$, require workers with specific skills. Each variety requires a different technology that is owned by one firm only. To produce any $\alpha$-variety, the firm that owns the technology incurs a fixed cost $\kappa_{\alpha}$ and requires $\varpi_{\alpha}{ }^{-1}$ units of skilled labor, all per unit of time. That is, to produce $z_{\alpha}$ units of an $\alpha$ variety, a firm demands an amount of labor given by

$$
h_{\alpha}=\kappa_{\alpha}+\varpi_{\alpha}^{-1} z_{\alpha}
$$

its employment. ${ }^{10}$ The larger is $\varpi_{\alpha}$, the less labor the production of each variety requires, and the more productive the activity is. Let $W_{\alpha}$ denote the nominal wage rate earned by workers employed by $\alpha$-variety producing firms. All such firms in a given city set the same monopolistic price, at the symmetric equilibrium, for each of their varieties of $\alpha$ - products, $p_{\alpha}$. I develop the wage setting model below after I complete the description of frictions in the labor market. ${ }^{11}$ 
The technology requires that both $\alpha$ - and $\beta$ - industry goods be available in the economy, though they do not need to operate necessarily in each city, since both types of varieties are tradeable. So, principle, there could be cities that contain both industries, diversified or mixed cities, or cities that specialize either in the $\alpha-$ or in the $\beta$ - industries, provided that such different city types are populated by the right skill mix. I return below to this possibility.

The typical firm in a city specializing in $\alpha$-varieties faces a price $P_{\alpha}$ for its output $Y_{\alpha}$ of the final consumption good. The price will be expressed in terms of the ideal price index. Optimizing ${ }^{12}$ with respect to each input $z_{\alpha, \alpha}$ and $z_{\alpha,-\alpha}$, respectively, gives the usual result that the demand for each variety is isoelastic in the price:

$$
\phi \frac{P_{\alpha} Y_{\alpha}}{\left[m_{\alpha} z_{\alpha, \alpha}^{1-\frac{1}{\sigma}}+m_{\alpha}\left(n_{\alpha}-1\right) z_{\alpha,-\alpha}^{1-\frac{1}{\sigma}}\right]} z_{\alpha, \alpha}^{-\frac{1}{\sigma}}=p_{\alpha, \alpha} .
$$

Correspondingly, for each imported intermediate variety we have:

$$
\phi \frac{P_{\alpha} Y_{\alpha}}{\left[m_{\alpha} z_{\alpha, \alpha}^{1-\frac{1}{\sigma}}+\left(n_{\alpha}-1\right) m_{\alpha} z_{\alpha,-\alpha}^{1-\frac{1}{\sigma}}\right]} z_{\alpha,-\alpha}^{-\frac{1}{\sigma}}=p_{\alpha,-\alpha},
$$

where for simplicity I ignore time subscripts. Due to iceberg shipping costs, whereby of a unit of a variety shipped only fraction $\tau$ survives, $0<\tau<1$, the effective price of an imported good is greater than that of a domestically produced one by a factor $\frac{1}{\tau}, p_{\alpha,-\alpha, t}=p_{\alpha, \alpha t} \frac{1}{\tau}$. From (5) and (6) we have that:

$$
z_{\alpha,-\alpha}=\tau^{\sigma} z_{\alpha, \alpha} .
$$

Similarly, the first order conditions for the demands for $\beta$-varieties by a city specializing in $\alpha$-varieties are given by:

$$
(1-\phi) \frac{P_{\alpha} Y_{\alpha}}{\left[n_{\beta} m_{\beta} z_{\beta, \alpha}^{1-\frac{1}{\sigma}}\right]} z_{\beta, \alpha}^{-\frac{1}{\sigma}}=p_{\beta} \frac{1}{\tau},
$$

where I use the assumption of iceberg costs to to write $p_{\beta t} \frac{1}{\tau}$ for the price of $\beta$-varieties imported by an $\alpha$-type city. The counterparts of equations (5), (6) and (8) for the cities specializing in $\beta$ varieties may be obtained in like manner. Therefore,

$$
z_{\beta,-\beta}=\tau^{\sigma} z_{\beta, \beta} .
$$

These necessary conditions yield:

$$
\begin{aligned}
& \phi P_{\alpha} Y_{\alpha}=p_{\alpha} \tilde{n}_{\alpha} m_{\alpha} z_{\alpha, \alpha} ;(1-\phi) P_{\alpha} Y_{\alpha}=p_{\beta} \frac{1}{\tau} n_{\beta} m_{\beta} z_{\beta, \alpha} ; \\
& \phi P_{\beta} Y_{\beta}=p_{\alpha} \frac{1}{\tau} n_{\alpha} m_{\alpha} z_{\alpha, \beta} ;(1-\phi) P_{\beta} Y_{\beta}=p_{\beta} \tilde{n}_{\beta} m_{\beta} z_{\beta, \beta},
\end{aligned}
$$


where the auxiliary variables $\tilde{n}_{j}$, defined as

$$
\tilde{n}_{j}=1+\left(n_{j}-1\right) \tau^{\sigma-1}, j=\alpha, \beta,
$$

denote the number of cities where $j$-varieties are produced, adjusted to account for intercity shipping costs. The demands for intermediates can be solved for explicitly, after trade balance is introduced, that is spending by all $\beta$ - cities on $\alpha$-varieties should be equal to spending by all $\alpha$-cities on $\beta$-varieties. If all varieties used are produced domestically, then

$$
n_{\beta} \phi P_{\beta} Y_{\beta}=n_{\alpha}(1-\phi) P_{\alpha} Y_{\alpha}
$$

This and (10-11) yield:

$$
n_{\beta} \tau^{-1} p_{\alpha} n_{\alpha} m_{\alpha} z_{\alpha, \beta}=n_{\alpha} \tau^{-1} p_{\beta} n_{\beta} m_{\beta} z_{\beta, \alpha},
$$

which together with conditions for equilibrium in the market for each variety,

$$
z_{\alpha, \alpha} \tilde{n}_{\alpha}+n_{\beta} \tau^{-1} z_{\alpha, \beta}=z_{\alpha} ; n_{\alpha} \tau^{-1} z_{\beta, \alpha}+\tilde{n}_{\beta} \tau^{-1} z_{\beta, \beta}=z_{\beta}
$$

yields the allocations of each intermediate to the production of the final good:

$$
\begin{aligned}
& z_{\alpha, \alpha}=\frac{\phi}{\tilde{n}_{\alpha}} z_{\alpha}, \quad z_{\alpha, \beta}=\frac{(1-\phi) \tau}{n_{\beta}} z_{\alpha} \\
& z_{\beta, \alpha}=\frac{\phi \tau}{n_{\alpha}} z_{\beta}, \quad z_{\beta, \beta}=\frac{(1-\phi)}{\tilde{n}_{\beta}} z_{\beta} .
\end{aligned}
$$

\subsection{Production of Varieties and Employment}

Hiring by each of the firms producing intermediate varieties is subject to frictions. Following the standard DMP approach, for a firm producing an $\alpha$-variety, let $h_{\alpha, t}$ denote employment, $q\left(\theta_{\alpha, t}\right)$ the rate at which employment prospects arrive per vacancy, $\theta_{\alpha, t}$ the ratio of vacancies to unemployment for each firm, $V_{\alpha, t}$ the stock of vacancies posted by an $\alpha$-firm, and $\delta_{\alpha}$ the rate at which jobs break up. I follow Ziesimer's (2003) extension of the Pissarides model to production with a range of intermediates, and thus have:

$$
\dot{h}_{\alpha, t}=q\left(\theta_{\alpha, t}\right) V_{\alpha, t}-\delta_{\alpha} h_{\alpha, t} .
$$

This can be expressed alternatively in terms of the quantity of each variety, $z_{\alpha, t}$,

$$
\dot{z}_{\alpha, t}=\varpi_{\alpha} q\left(\theta_{\alpha, t}\right) V_{\alpha, t}-\delta_{\alpha}\left[\varpi_{\alpha} \kappa_{\alpha}+z_{\alpha, t}\right]
$$

Each intermediate producing firm sets production $z_{\alpha, t}$, price $p_{\alpha, t}$, and vacancies $V_{\alpha, t}$, so as to maximize expected profit:

$$
\int_{0}^{\infty} e^{-\rho t}\left[p_{\alpha, t} z_{\alpha, t}-W_{\alpha, t}\left[\kappa_{\alpha}+\varpi_{\alpha}{ }^{-1} z_{\alpha, t}\right]-p_{\alpha, t} \gamma V_{\alpha, t}\right] d t
$$


where $\gamma$ denotes the cost per unit of time for each vacancy, denominated in units of the respective variety. Working in the standard fashion, if $\lambda$ denotes the Lagrange multiplier adjoining the evolution of output equation (17), the first order condition with respect to $V_{\alpha, t}{ }^{13}$ by using the current value Hamiltonian yields:

$$
\lambda=\frac{\gamma p_{\alpha, t} \varpi_{\alpha}^{-1}}{q\left(\theta_{\alpha, t}\right)}
$$

The first-order condition ${ }^{14}$ with respect to $z_{\alpha, t}$, yields, after assuming a steady state for $\lambda$ and using for it the above value ${ }^{15}$, the pricing equation:

$$
p_{\alpha, t}=\frac{\sigma}{\sigma-1}\left[\varpi_{\alpha}{ }^{-1} W_{\alpha, t}+\left(\delta_{\alpha}+\rho\right) \frac{\gamma \varpi_{\alpha}^{-1}}{q\left(\theta_{\alpha, t}\right)} p_{\alpha, t}\right] .
$$

This is the counterpart here of the job creation condition in the canonical model of Pissarides (2000), p. 12, Eq. (1.9), except for the fact that the monopolistic competition model introduces a markup, $\frac{\sigma}{\sigma-1}$ over unit cost in the standard fashion. The price covers the cost of labor per unit of time which includes the wage costs, $\varpi_{\alpha}{ }^{-1} W_{\alpha, t}$, plus the expected capitalized value of the future stream of hiring costs foregone. The latter involves costs per vacancy, $\gamma \varpi_{\alpha}^{-1} p_{\alpha, c, t}$, adjusted for the expected length of vacancy, $\frac{1}{q\left(\theta_{\alpha, t}\right)}$, and the probability of job destruction and time preference, $\delta_{\alpha}+\rho .{ }^{16}$

Along the optimum path, free entry by potential $\alpha$-variety producing firms ensures that profits per unit of time are driven to zero at every point in time:

$$
p_{\alpha, c} z_{\alpha}-W_{\alpha}\left(\varpi_{\alpha}^{-1} z_{\alpha}+\kappa_{\alpha}\right)-p_{\alpha, c} \gamma V_{\alpha}=0
$$

At the steady state, using the pricing formula (19) together with (17), (22) and (20) we obtain the equilibrium output and employment respectively as:

$$
\begin{gathered}
z_{\alpha}=\frac{(\sigma-1) \varpi_{\alpha}-\frac{\rho \gamma \sigma}{q\left(\theta_{\alpha}\right)}}{1+\frac{\rho \gamma \sigma}{q\left(\theta_{\alpha}\right)} \varpi_{\alpha}^{-1}} \kappa_{\alpha} ; \\
h_{\alpha}=\frac{\sigma \kappa_{\alpha}}{1+\frac{\rho \gamma \sigma}{q\left(\theta_{\alpha}\right)} \varpi_{\alpha}^{-1}} .
\end{gathered}
$$

The corresponding level of vacancies at the steady state equilibrium is $V_{\alpha}=\frac{\delta_{\alpha}}{q\left(\theta_{\alpha}\right)}\left[\varpi_{\alpha}{ }^{-1} z_{\alpha}+\kappa_{\alpha}\right]$, which in view of (22) becomes:

$$
V_{\alpha}=\frac{\delta_{\alpha}}{q\left(\theta_{\alpha}\right)} \frac{\sigma \kappa_{\alpha}}{1+\frac{\rho \gamma \sigma}{q\left(\theta_{\alpha}\right)} \varpi_{\alpha}^{-1}}
$$

Both expressions for output and the labor requirements for each variety, Eq. (21) and (22) above, are functions of $\theta_{\alpha}$, labor market tightness for each variety, which in turn imply 
a similar relationship for $V_{\alpha},(23)$, as a function of $\theta_{\alpha}$. We see shortly that the rate at which employment prospects arrive per vacancy, $q\left(\theta_{\alpha}\right)$, decreases with labor market tightness; thus equilibrium output ${ }^{17}$ and employment ${ }^{18}$ for each variety decreases in labor market tightness. Other things being equal, this would imply a lower unemployment rate. An increase in productivity increases output and employment for each of the varieties produced. Below we examine the effect of such a change on the number of varieties produced at equilibrium.

\section{Behavior of Individuals}

I follow Wasmer and Zenou (2002), as adapted by Ioannides (2013), Ch. 5, and derive expressions for expected lifetime utility, income, in a continuous-time model at steady state, under the assumption that individuals lose their jobs when employed, and search for new jobs only when unemployed, both at constant probabilities per unit of time, and may borrow and lend at a constant rate of interest $\rho$.

Let $j$ index individuals by skill type, $j=\alpha, \beta$, as indicated by the industry where they qualify for employment. The derivation proceeds by first solving for an individual's expected lifetime income, conditional on being unemployed, and employed, $\Omega_{j u}(\ell), \Omega_{j e}(\ell)$, respectively, as functions of distance from the CBD. Let the commuting costs per unit of time for, respectively, an employed, and an unemployed person, be linear functions of the distance from the $\mathrm{CBD}, \bar{a}_{j e} \ell, \bar{a}_{j u} \ell$. The rate of unemployment compensation (or home production) per unit of non-commuting time is denominated in terms of the good produced of the industry of employment $j=\alpha, \beta, b_{j}=b p_{j}$, where $p_{j}$ is the price of good $j$. Jobs break up at constant rates $\delta_{j}$ in industry $j$, and the rate at which unemployed workers find jobs in industry $j$ is denoted by $\pi_{j}$. If unsubscripted, it denotes the number $\pi$. Finally, $R(\ell)$ is the land rental rate at location $\ell$, and, $\bar{R}$ : total land rentals per capita in a city, both per unit of time.

The expected values of unemployment and employment $\Omega_{j u}, \Omega_{j e}$ satisfy the following Bellman equations:

$$
\begin{gathered}
\rho \Omega_{j u}(\ell)=b_{j} p_{j}\left(1-\bar{a}_{j u} \ell\right)+\pi_{j}(\ell)\left[\Omega_{j e}(\ell)-\Omega_{j, u}(\ell)\right]+\bar{R}-R(\ell), \\
\rho \Omega_{j e}(\ell)=W_{j}\left(1-\bar{a}_{j e} \ell\right)+\delta_{j}\left[\Omega_{j u}(\ell)-\Omega_{j e}(\ell)\right]+\bar{R}-R(\ell) .
\end{gathered}
$$

The steady state rate of unemployment for an individual who is employed in industry $j$ must be such that flows into unemployment equal flows out of unemployment. That is: $\delta_{j}\left(1-u_{j}\right)=u_{j} \pi_{j}$, which by solving for $u_{i}$ yields:

$$
u_{j}=\frac{\delta_{j}}{\delta_{j}+\pi_{j}} .
$$


The steady state unemployment rate decreases as the job finding rate $\pi_{j}$ increases. In most of the paper, the individual unemployment rate does not depend on $\ell$.

The expected present value of lifetime income of an individual of type $j$ at location $\ell$ along a steady state of the search process is given by: $\omega_{j}(\ell)=\left(1-u_{j}\right) \Omega_{e}+u_{j} \Omega_{i u}$. From (24-26), this may be expressed as:

$$
\rho \omega_{\alpha}(\ell)=\bar{R}-R(\ell)+\overline{\mathcal{D}}_{\alpha}-\mathcal{D}_{\alpha} \ell, r \omega_{\beta}(\ell)=\bar{R}-R(\ell)+\overline{\mathcal{D}}_{\beta}-\mathcal{D}_{\beta} \ell
$$

where the auxiliary functions $\left(\overline{\mathcal{D}}_{\alpha}, \overline{\mathcal{D}}_{\beta} ; \mathcal{D}_{\alpha}, \mathcal{D}_{\beta}\right)$ are defined as follows, $j=\alpha, \beta$ :

$$
\begin{gathered}
\overline{\mathcal{D}}_{j} \equiv \frac{\delta_{j}}{\delta_{j}+\pi_{j}} b_{j} p_{j}+\frac{\pi_{j}}{\delta_{j}+\pi_{j}} W_{j} . \\
\mathcal{D}_{j} \equiv \frac{\delta_{j}}{\delta_{j}+\pi_{j}} \bar{a}_{j u} b_{j} p_{j}+\frac{\pi_{j}}{\delta_{j}+\pi_{j}} W_{j} \bar{a}_{j e} .
\end{gathered}
$$

\subsection{An Application to the Case of Social Learning}

As an application, I assume that when the two skilled types coexist in the same city, $\beta-$ types experience social learning which results in their becoming $\alpha$-types with a propensity given by $\delta_{\beta, \alpha}$. This can be expressed by modifying Eq. (24) for $j=\beta$ as follows:

$$
r \Omega_{\beta, u}(\ell)=b_{j} p_{\beta}\left(1-A_{\beta, u}(\ell)\right)+\pi_{\beta}(\ell)\left[\Omega_{\beta, e}(\ell)-\Omega_{\beta, u}(\ell)\right]+\delta_{\beta, \alpha}\left[\Omega_{\alpha, u}(\ell)-\Omega_{\beta, u}(\ell)\right]+\bar{R}-R(\ell) .
$$

If we were to to treat the two employment states symmetrically and allow for transitions to $\alpha$ even when $\beta$ types are employed, then a simpler expression for expected utility follows which clarifies the advantages of social learning.

\subsection{The Matching Model}

I specify the employment and unemployment probability in the classic DMP fashion. Let $s_{j}$ denote the efficiency of search by a type $j$-person, when unemployed, $U_{j}$ denote the stock of all unemployed type $j$-workers associated with a particular $j$-firm, $V_{j}$ the stock of vacancies for jobs for which $j$-types qualify, and $\bar{s}$ the average efficiency of search by all unemployed workers in a city. The rate of contacts between unemployed workers and vacancies per unit of time is specified via a matching function [Pissarides (1985; 2000)], as a function of $\left(\bar{s} U_{j}, V_{j}\right)$, denoted by

$$
M\left(\bar{s} U_{j}, V_{j}\right) .
$$

Following Pissarides, I assume that the matching function of vacancies with unemployed workers, $M\left(\bar{s} U_{j}, V_{j}\right)$, exhibits constant returns to scale with respect to both of its arguments, 
the effective stock of unemployed and the stock of vacancies, respectively. ${ }^{19}$ The probability that an individual of type $j$ with search efficiency $s_{j}$ will have a contact during a small interval of time $(t, t+d t)$ is given by

$$
\pi_{j} d t=\frac{M\left(\bar{s} U_{j}, V_{j}\right)}{U_{j}} \frac{s_{j}}{\bar{s}} d t=M\left(1, \theta_{j}\right) s_{j} d t .
$$

This is rewritten, by using the linear homogeneity property of the matching function, as a function of the effective tightness of a city's labor market for $j$-types, $\theta_{j}, \theta_{j}=\frac{V_{j}}{U_{j} \bar{s}}$ :

$$
\pi_{j}=\theta_{j} q\left(\theta_{j}\right) s_{j}
$$

where $q\left(\theta_{j}\right) \equiv M\left(\frac{1}{\theta_{j}}, 1\right), q^{\prime}=-M_{1} \frac{1}{\theta j^{2}}<0$, denotes the rate at which unemployed workers arrive at each searching vacancy (firm). Therefore, the greater is $\theta_{j}$, the tighter the labor market is, and the lower the probability of contacts, $q$, for each firm. It follows from (33) by differentiation that an individual's job contact probability, on the other hand, is increasing and concave in labor market tightness. Technological improvements, arguably due to information and communication technology, may be seen as increasing average search intensity $\bar{s}$. Or, an individual may increase her own search intensity $s_{j}$, relative to $\bar{s}$.

Anticipating the discussion below, each industry is analyzed at a symmetric equilibrium among all intermediate varieties-producing firms of the same type, at which labor market tightness, and the respective stocks of unemployed individuals and vacant jobs are equalized. We will rely on the constant returns to scale assumption for the matching function and aggregate matching up to the level of the industry.

\section{The Urban Structure}

The urban structure in this paper is assumed to consist of homogeneous cities of either type $\alpha$ or $\beta$, that is, each city is populated by individuals of the same skill. Locational equilibrium within each city of either type requires that otherwise identical individuals be indifferent as to where they locate. I thus impose that expected lifetime utility be equalized across all locations within each city. In a homogeneous city, all individuals employ the same search intensity, so that the job matching probability is independent of specific location within the city. For spatial equilibrium, the land rental rate must vary with location so as to equalize expected lifetime income across all locations. Thus, the bid rental rate associated with a particular individual type $R(\ell)$ reflects the value of accessibility to the CBD.

In contrast, one can think of diversified cities whose populations are heterogeneous, consisting of individuals of either skill type. Under our assumptions, diversified cities may host 
both industries. The specific analytics of heterogenous cities in the context of this paper are straightforward to develop. First, if both labor types coexist, it is easy to show that they are spatially segregated. Competition in the land market along with the linearity of rental bid functions imply that there is in general a single switch-over point, $\hat{\ell}$, where land rental bid functions ar equalized: $R_{\alpha}(\hat{\ell})=R_{\beta}(\hat{\ell})$. Furthermore, if $\beta$ types inhabit the outer part of the city and if the opportunity cost of land at the edge $\bar{\ell}$, is equal to 0 , then $R_{\beta}(\bar{\ell})=0$. Furthermore, it is important to allow for advantages for mixed cities in order to offset the disadvantages of congestion. Such an advantage could be the presence of social learning (see section 3.1), whereby by living in the same city, lower-skilled individuals experience the likelihood of becoming higher skilled.

\subsection{City Types and Spatial Equilibrium}

Working from (27), for either city type, we have that for $\omega_{j}(\ell)$ to be constant across all locations and under the assumptions that the opportunity cost of land at the city's edge $\bar{\ell}$, is equal to 0 and that employment probabilities are independent of $\ell$, then $R_{\beta}(\bar{\ell})=0$. Spatial equilibrium within the $j$-populated area of the city implies a land rental function

$$
R_{j}(\ell)=\mathcal{D}_{j}(\bar{\ell}-\ell)
$$

which is linear in $\ell$.

Under the assumption that employment probabilities are independent of $\ell$, the land rental functions from (34) may be easily integrated. Then, by expressing the equilibrium lifetime utilities net of the redistribution of total land rents, we have the following expressions, which are of course independent of $\ell{ }^{20}$ For homogeneous cities:

$$
\omega_{j}^{*}=\overline{\mathcal{D}}_{j}-\frac{2}{3} \mathcal{D}_{j} \bar{\ell}_{j}
$$

Since land is consumed at the unit level only, it follows that

$$
N_{j}=\pi \hat{\ell}_{j}^{2}
$$

Thus, equilibrium utilities are written in terms of populations of different skill types. They decrease with city size, which is also due to congestion. Other things being equal, the utility associated with each type living in a mixed city is inferior to that afforded in specialized cities. Therefore, other things being equal, there has to be advantage to mixed cities, or else they would not be observed. The fact that mixed cities save on shipping costs is an advantage. 


\subsection{Wage Setting in Specialized Cities}

Following the Mortensen and Pissarides assumption that the typical intermediates-producing firm opens vacancies as long as their expected value is zero yields an expression for the value of a filled job: $\frac{\gamma p_{\alpha, c, t}}{q\left(\theta_{\alpha}\right)}$. From the pricing condition (19), the value of a filled job may be expressed as: $\frac{1}{\delta_{\alpha}+\rho}\left[\frac{\sigma-1}{\sigma} \varpi_{\alpha} p_{\alpha, c, t}-W_{\alpha, c, t}\right]$. It enters the objective function for the Nash bargaining wage setting problem, Eq. (37) below. That is, the typical intermediates-producing firm in an $\alpha$-producing city and the typical worker jointly choose $W_{\alpha, t}$ so as to maximize ${ }^{21}$ :

$$
\left[\overline{\mathcal{D}}_{\alpha}-\frac{2}{3} \mathcal{D}_{\alpha} \bar{\ell}_{\alpha}\right]^{\vartheta}\left[\frac{\sigma-1}{\sigma} \varpi_{\alpha} p_{\alpha, t}-W_{\alpha, t}\right]^{1-\vartheta}
$$

where $\vartheta, 0<\vartheta<1$, is a parameter indicating the relative bargaining of an individual, with the firm's being denoted by $1-\vartheta$. This formulation presumes symmetry across all intermediates-producing firms. The solution for the wage rate, the counterpart here of what is known as in the DMP model as the "wage curve," is:

$$
W_{\alpha}=\vartheta \frac{\sigma-1}{\sigma} \varpi_{\alpha} p_{\alpha}-(1-\vartheta) \frac{\delta_{\alpha}}{\pi_{\alpha}} \frac{1-\frac{2}{3} N_{\alpha}^{\frac{1}{2}} \bar{a}_{u, \alpha}^{\prime}}{1-\frac{2}{3} N_{\alpha}^{\frac{1}{2}} \bar{a}_{e, \alpha}^{\prime}} b p_{\alpha} .
$$

Note that it depends explicitly on city size provided that the commuting costs depend on the employment state. The wage curve plays the role of labor supply: other things being equal, the wage rate increases in the respective labor market tightness. The associated expression for expected nominal income per period in a type- $\alpha$ city is:

$$
\vartheta \frac{\pi_{\alpha}}{\pi_{\alpha}+\delta_{\alpha}}\left[1-\frac{2}{3} N_{\alpha}^{\frac{1}{2}} \bar{a}_{e, \alpha}^{\prime}\right] \frac{\sigma-1}{\sigma} \varpi_{\alpha} p_{\alpha}+\vartheta \frac{\delta_{\alpha}}{\pi_{\alpha}+\delta_{\alpha}}\left[1-\frac{2}{3} N_{\alpha}^{\frac{1}{2}} \bar{a}_{u, \alpha}^{\prime}\right] b p_{\alpha},
$$

and similarly for a type- $\beta$ city. Real income follows by dividing expected nominal income by the respective ideal price index. The ideal price index ${ }^{22}$ accounts for the effective range of intermediate varieties used. In particular, a specialized city of type $\alpha$, imports all $\beta$ varieties, and there are $m_{\beta} n_{\beta}$ of them, incurring shipping costs, and correspondingly for cities of type $\beta$, that import all $\alpha$ varieties, of which there are $m_{\alpha} n_{\alpha}$. Therefore, the price indices (inclusive of shipping costs) are, respectively:

$$
P_{\alpha}^{*}=p_{\alpha}^{\phi} p_{\beta}^{1-\phi}\left[m_{\alpha} \tilde{n}_{\alpha}\right]^{\frac{\phi}{1-\sigma}}\left[m_{\beta} n_{\beta} \tau^{\sigma-1}\right]^{\frac{1-\phi}{1-\sigma}}, P_{\beta}^{*}=p_{\alpha}^{\phi} p_{\beta}^{1-\phi}\left[m_{\alpha} n_{\alpha} \tau^{\sigma-1}\right]^{\frac{\phi}{1-\sigma}}\left[m_{\beta} \tilde{n}_{\beta}\right]^{\frac{1-\phi}{1-\sigma}},
$$

where the auxiliary variables $\tilde{n}_{j}, j=\alpha, \beta$, defined in (12) above, denote the number of cities adjusted for shipping costs. 


\subsubsection{Labor Market Equilibrium in Specialized Cities}

Labor market equilibrium is entirely defined in terms of labor market tightness. The job creation condition (19) may be rewritten here simply as $\frac{\gamma}{q\left(\theta_{\alpha}\right)}=\frac{1}{\delta_{\alpha}+\rho}\left[\frac{\sigma-1}{\sigma} \varpi_{\alpha}-\frac{W_{\alpha, t}}{p_{\alpha, t}}\right]$, yields a downwards sloping curve in $(\theta, W)$ space. Using the solution for $\frac{W_{\alpha, c, t}}{p_{\alpha, c, t}}$ from the bargaining outcome, (38), yields

$$
\frac{\gamma}{q\left(\theta_{\alpha}\right)}=\frac{1-\vartheta}{\delta_{\alpha}+\rho}\left[\frac{\sigma-1}{\sigma} \varpi_{\alpha}+\frac{\delta_{\alpha}}{\pi_{\alpha}} \frac{1-\frac{2}{3} N_{\alpha}^{\frac{1}{2}} \bar{a}_{\alpha u}-\frac{2}{3} N_{\alpha}^{\frac{1}{2}} \bar{a}_{\alpha e}}{1-}\right.
$$

The left hand side is increasing in $\theta_{\alpha}$ and the right hand side is decreasing in $\theta_{\alpha}$ via its effect on $\pi_{\alpha}$. Thus, (41) uniquely determines, in terms of exogenous variables and parameters, labor market tightness in a specialized city. Higher productivity increases equilibrium labor market tightness, which in turn implies higher employment rate and lower unemployment rate. The right hand side increases (decreases) with $N_{\alpha}^{\frac{1}{2}}$, provided that $\bar{a}_{\alpha, e}>(<) \bar{a}_{\alpha, u}$. It is reasonable to assume that $\bar{a}_{\alpha e}>\bar{a}_{\alpha u}$ — the unemployed do not have to commute to the $\mathrm{CBD}$ as frequently as the employed. Thus, the implicit solution of (41) can be written so as to summarize all effects as:

$$
\theta_{\alpha}=\Theta\left(\begin{array}{ccccc}
N_{\alpha} & ; & \varpi_{\alpha}, & b_{\alpha}, & \delta_{\alpha} \\
(+) & (+) & (+) & (?)
\end{array}\right.
$$

A larger city size is associated with greater labor market tightness and therefore higher employment rate and lower unemployment rate. The effect of the job destruction rate is positive (negative) if $\frac{\rho}{\pi_{\alpha}} \frac{1-\frac{2}{3} N_{\alpha}^{\frac{1}{2}} \bar{a}_{\alpha u}}{1-\frac{2}{3} N_{\alpha}^{\frac{1}{2}} \bar{a}_{\alpha e}} b_{\alpha}>\quad(<) \frac{\sigma-1}{\sigma} \varpi_{\alpha}$. Unemployment is independent of city size only if the loss of time due to commuting is independent of employment status: $\bar{a}_{j e}=\bar{a}_{j u}=\bar{a}, j=\alpha, \beta$. In that case, employed and unemployed would differ only with respect to the rate of pay, wage rate versus unemployment compensation. Also, this margin provides the tradeoff for endogenizing search intensity. Greater intensity improves the likehihood of employment, but requires more frequent visits to the CBD. See Zenou (2009a, b).

\subsection{Beveridge Curve}

The Beveridge curve, an empirical tool that the study of labor markets with frictions aimed at predicting [Pissarides (1986); Pissarides (2000), p. 32], has been adopted by the U.S. Bureau of Labor Statistics a standard device in tracking labor market conditions. ${ }^{23}$ Plotting the vacancy rate against the unemployment rate allows one to compare the impact of the business cycle on the labor market. 
The Beveridge curve is an "accounting" relationship [see Diamond (2011); Mortensen (2011); Pissarides (2011)] in the sense it expresses "combinations of vacancies and unemployment that are consistent with equality between the entry into unemployment and the exit from it [Pissarides (2011), p. 1095)]. I apply this concept to each each intermediatevariety producing firm by defining the vacancy rate as the ratio of vacancies to vacancies plus employment. Using (22) and (23) yields:

$$
v_{\alpha}=\frac{V_{\alpha}}{V_{\alpha}+h_{\alpha}}=\frac{\delta_{\alpha}}{\delta_{\alpha}+q\left(\theta_{\alpha}\right)} .
$$

Thus, the vacancy rate increases in $\theta_{\alpha}$, labor market tightness and the steady state unemployment rate decreases. Therefore, changes in $\theta_{\alpha}$ trace the movement along a curve in $(u, v)$ space, a Beveridge curve for each intermediate variety producing firm.

Applying the above definition at the city level and for each city type at the symmetric equilibrium, we have:

$$
v_{\alpha, N_{\alpha}}=\frac{m_{\alpha} V_{\alpha}}{m_{\alpha} V_{\alpha}+m_{\alpha} h_{\alpha}}=\frac{\delta_{\alpha}}{\delta_{\alpha}+q\left(\theta_{\alpha}\right)} .
$$

Thus, city-level Beveridge curves coincide with the respective firm-specific ones in homogeneous cities: $v_{\alpha, N_{\alpha}}=v_{\alpha}$. We return below to the definition of aggregate, economy-wide Beveridge curves. Once we have defined aggregate equilibrium, we confirm this definition at equilibrium.

The impact of changes in productivity $\varpi_{\alpha}$ on $\theta_{\alpha}$ depends from (41) on city size. Larger cities are associated with Beveridge curves closer to the origin. With constant rates of job destruction, it is evident from the above definition that the properties of the Beveridge curve reflect the matching function. The Beveridge curve has become particularly useful in tracing the evolution of the business cycle. It follows directly from the definitions that, for any given level of labor tightness, the more efficient is matching of job openings with workers, for any given level of labor tightness, the nearer is the Beveridge curve to the axes. Where we are on the Beveridge curve for an $\alpha$-variety producing firm depends on the value of labor market tightness. I note that the above analysis treats job destruction as independent of productivity. Allowing for job destruction to depend on shocks to productivity $\varpi_{\alpha}, \varpi_{\beta}$ requires suitably adapting the firms' search model [see Mortensen and Pissarides (1999)].

\subsection{Aggregate Equilibrium in an Economy with Specialized Cities}

With the number of cities hosting skilled labor of type $\alpha(\beta)$ given by $n_{\alpha}\left(n_{\beta}\right)$, and their respective populations being $N_{\alpha}\left(N_{\beta}\right)$, for national labor market equilibrium we have,

$$
n_{\alpha} N_{\alpha}=\bar{N}_{\alpha}, \quad n_{\beta} N_{\beta}=\bar{N}_{\beta},
$$


where $\bar{N}_{\alpha}$ and $\bar{N}_{\beta}$ denote the total population of labor of the respective type.

In an $\alpha$-type city, the demand for labor for the production of all $\alpha$ varieties, $m_{\alpha} h_{\alpha}$, is equal to expected labor supply, $\left(1-u_{\alpha}\right) \bar{H}_{e, \alpha}$, where $\bar{H}_{e, \alpha}$ is net labor available for production, which accounts for time spent on commuting when employed. That is $\int_{0}^{\left(\frac{N_{j}}{\pi}\right)^{\frac{1}{2}}}\left[1-\bar{a}_{e} \ell\right] 2 \pi \ell d \ell$ :

$$
\bar{H}_{j e}\left(N_{j}\right)=N_{j}\left(1-\frac{2}{3} a_{j, e} N_{j}^{\frac{1}{2}}\right), j=\alpha, \beta,
$$

where $a_{j e} \equiv \bar{a}_{j e} \pi^{-\frac{1}{2}}$. Similarly, the stock of unemployed labor is given by $u_{j} \bar{H}_{j u}\left(N_{j}\right)$, where instead of $a_{j e}$ in (46) we have $a_{j u} \equiv \bar{a}_{j u} \pi^{-\frac{1}{2}}$.

In an economy with an urban structure made up of specialized cities, equilibrium tightness is determined by (41) for each city type. The number of varieties used at equilibrium are determined by imposing equilibrium in the labor market in each city type. The demand for labor for the production of all varieties in a city of type $\alpha$, respectively $\beta$, is simply equal to expected employment:

$$
m_{\alpha} h_{\alpha}=\frac{\pi_{\alpha}}{\pi_{\alpha}+\delta_{\alpha}} \bar{H}_{\alpha e}, \quad m_{\beta} h_{\beta}=\frac{\pi_{\beta}}{\pi_{\beta}+\delta_{\beta}} \bar{H}_{\beta e}
$$

where each city's labor supply, $\bar{H}_{j e}, j=\alpha, \beta$, is given by (46) above. These conditions determine the range of varieties as function of labor market tightness in the respective city type: $m_{\alpha}=m_{\alpha}\left(\theta_{\alpha}, \bar{H}_{e, \alpha}\right), m_{\beta}=m_{\beta}\left(\theta_{\beta}, \bar{H}_{e, \beta}\right)$, given all parameters describing the productivity characteristics of the technologies producing the differentiated varieties. Since employment for each variety decreases in labor market tightness and employment rate increases, it follows from (47) that the range of varieties increases with labor market tightness:

$$
\frac{\partial m_{j}\left(\theta_{j}, \bar{H}_{e, j}\right)}{\partial \theta_{j}}>0 ; \quad \frac{\partial m_{j}\left(\theta_{j}, \bar{H}_{e, j}\right)}{\partial \bar{H}_{e, j}}>0, j=\alpha, \beta .
$$

With $\left(z_{\alpha}, z_{\beta}\right)$ as known functions of $\left(\theta_{\alpha}, \theta_{\beta}\right)$ from $\left.(21)\right)$, and $m_{\alpha}=m_{\alpha}\left(\theta_{\alpha}, \bar{H}_{e, \alpha}\right), m_{\beta}=$ $m_{\beta}\left(\theta_{\beta}, \bar{H}_{e, \beta}\right)$ implicitly determined by (47), the equilibrium terms of trade, $\frac{p_{\alpha}}{p_{\beta}}$, given by (13), are thus determined as a function of $\left(\theta_{\alpha}, \bar{H}_{e, \alpha} ; \theta_{\beta}, \bar{H}_{e, \beta}\right)$. By Walras' law, at the price ratio that satisfies this condition, and given the free entry (20) and the pricing (19) conditions, all markets clear. Presence of intercity shipping costs of the iceberg type does not affect this conclusion.

At equilibrium, the terms of trade from (13) and (14) become:

$$
\frac{p_{\alpha}}{p_{\beta}}=\frac{\phi}{1-\phi} \frac{n_{\beta}}{n_{\alpha}} \frac{m_{\beta}}{m_{\alpha}} \frac{z_{\beta}}{z_{\alpha}} .
$$


By writing $m_{\alpha} z_{\alpha}=\frac{z_{\alpha}}{h_{\alpha}} m_{\alpha} h_{\alpha}$ we have after using the steady state solutions for intermediate output and employment, (21) and (22), the labor market equilibrium condition (47) and the job creation condition (41):

$$
m_{\alpha} z_{\alpha}=\left[\frac{\sigma-1}{\sigma} \varpi_{\alpha} \frac{\pi_{\alpha}}{\pi_{\alpha}+\delta_{\alpha}}-\frac{\rho \gamma}{\frac{\delta_{\alpha}}{\theta_{\alpha}}+q\left(\theta_{\alpha}\right)}\right] \bar{H}_{\alpha e} .
$$

Or, after using (47):

$$
m_{\alpha} z_{\alpha}=\left[\frac{\delta_{\alpha}+\rho \vartheta}{1-\vartheta} \frac{\gamma}{\frac{\delta_{\alpha}}{\theta_{\alpha}}+q\left(\theta_{\alpha}\right)}-\frac{\delta_{\alpha}}{\pi_{\alpha}+\delta_{\alpha}} \frac{1-\frac{2}{3} N_{\alpha}^{\frac{1}{2}} \bar{a}_{\alpha u}}{1-\frac{2}{3} N_{\alpha}^{\frac{1}{2}} \bar{a}_{\alpha e}} b_{\alpha}\right] \bar{H}_{\alpha e}
$$

provided that the r.h.s. be positive. The latter imposes a condition among labor market tightness and the various parameters, including notably $\varpi_{\alpha}$. A sufficient condition for the positivity of the r.h.s. of (51) is:

$$
\theta_{\alpha}>\frac{\delta_{\alpha}(1-\vartheta)}{\left(\delta_{\alpha}+\rho \vartheta\right) \gamma}
$$

which amounts to a lower bound on labor market tightness. Eq. (51) is defines $m_{\alpha} z_{\alpha}$ as an implicit function of $\theta_{\alpha}$, which is increasing in labor market tightness $\theta_{\alpha}$.

Using (51) in (49), we have:

$$
\frac{p_{\alpha}}{p_{\beta}}=\frac{\phi}{1-\phi} \frac{n_{\beta}}{n_{\alpha}} \frac{\left[\frac{\delta_{\beta}+\rho \vartheta}{1-\vartheta} \frac{\gamma}{\frac{\delta_{\beta}}{\theta_{\beta}}+q\left(\theta_{\beta}\right)}-\frac{\delta_{\beta}}{\pi_{\beta}+\delta_{\beta}} \frac{1-\frac{2}{3} N_{\beta}^{\frac{1}{2}} \bar{a}_{\beta u}}{1-\frac{2}{3} N_{\beta}^{\frac{1}{2}} \bar{a}_{\beta e}} b_{\beta}\right]}{\left[\frac{\delta_{\alpha}+\rho \vartheta}{1-\vartheta} \frac{\gamma}{\frac{\delta_{\alpha}}{\theta_{\alpha}}+q\left(\theta_{\alpha}\right)}-\frac{\delta_{\alpha}}{\pi_{\alpha}+\delta_{\alpha}} \frac{1-\frac{2}{3} N_{\alpha}^{\frac{1}{2}} \bar{a}_{\alpha u}}{1-\frac{2}{3} N_{\alpha}^{\frac{1}{2}} \bar{a}_{\alpha e}} b_{\alpha}\right]} \bar{H}_{\beta e} .
$$

It thus follows from (53) that given number of cities and city sizes, an increase in labor market tightness of $\alpha$-type cities reduces its own terms of trade while it increases employment and reduces unemployment in such cities. This is due to the productivity enhancing role of the range of varieties. Even though the production of each variety decreases, when labor market tightness increases, the increase in the range and in the employment rate more than make up. Also, increase in the productivity of $\alpha$-varieties implies higher labor market tightness, which in turn induces increase in production which in turn leads to fall in their price.

In sum, given the number of cities and city populations of each type, job creation conditions for $\alpha$-type cities (41), and its counterpart for $\beta$ - type cities, determine labor market tightness in each city type, $\theta_{\alpha}, \theta_{\beta}$. Labor market tightness in turn determines employment at free entry equilibrium for each variety, and from the conditions for labor market equilibrium in each city, (47), the ranges of intermediates $m_{\alpha}, m_{\beta}$ are determined. The equilibrium terms of trade follow from (53), which establishes an one-to-one correspondence between 
labor market tightness in each city type and terms of trade. Here, labor market tightness variables act a bit like factor intensities in international trade models.

By using (45) and (46) to rewrite (53), we have:

$$
\frac{p_{\alpha}}{p_{\beta}}=\frac{\phi}{1-\phi} \frac{\bar{N}_{\beta}}{\bar{N}_{\alpha}} \frac{\left[\frac{\delta_{\beta}+\rho \vartheta}{1-\vartheta} \frac{\gamma \theta_{\beta}}{\pi_{\beta}+\delta_{\beta}}\left(1-\frac{2}{3} N_{\beta}^{\frac{1}{2}} \bar{a}_{\beta e} b_{\beta}\right)-\frac{\delta_{\beta}}{\pi_{\beta}+\delta_{\beta}}\left(1-\frac{2}{3} N_{\beta}^{\frac{1}{2}} \bar{a}_{\beta u}\right)\right]}{\left[\frac{\delta_{\alpha}+\rho \vartheta}{1-\vartheta} \frac{\gamma \theta_{\alpha}}{\pi_{\alpha}+\delta_{\alpha}}\left(1-\frac{2}{3} N_{\alpha}^{\frac{1}{2}} \bar{a}_{\alpha e} b_{\alpha}\right)-\frac{\delta_{\alpha}}{\pi_{\alpha}+\delta_{\alpha}}\left(1-\frac{2}{3} N_{\alpha}^{\frac{1}{2}} \bar{a}_{\alpha u}\right)\right]} .
$$

In view of (52), a larger population of each city type improves its own terms of trade.

By Walras' law, given city numbers and populations, $\left(n_{\alpha}, N_{\alpha} ; n_{\beta}, N_{\beta}\right)$, the equilibrium terms of trade from Eq. (53) together with equilibrium labor market tightness in each city type, given by (41), ensure that individuals's demand for output in each city must equal its supply. That is, individuals spend the flow of their permanent income on their city's output, ${ }^{24}$

$$
P_{\alpha} Y_{\alpha}=\text { expected nominal income }{ }_{\alpha} N_{\alpha},
$$

and similarly for $\beta$ cities, where expected nominal income ${ }_{\alpha}$ is given by (39).

Real income at equilibrium is given by (39), divided by the ideal price index for $\alpha$-type cities, $P_{\alpha}^{*}$, adjusted to account for intercity shipping costs associated with importing all $\beta$ varieties, that is (40), and vice versa for $\beta$-type cities. Therefore, given the equilibrium value of the terms of trade from (13), real nominal income is fully determined by the model. That is, the expression for nominal permanent income in (39) is homogeneous of degree one in $p_{\alpha}$, so that dividing it by the ideal price index yields an expression for real permanent income that is a function of the terms of trade $\left(\frac{p_{\alpha}}{p_{\beta}}\right)$, and, in addition, of the ranges of varieties and number of cities:

$$
\begin{gathered}
\left(\frac{p_{\alpha}}{p_{\beta}}\right)^{1-\phi}\left[m_{\alpha} \tilde{n}_{\alpha}\right]^{\frac{\phi}{\sigma-1}}\left[m_{\beta} n_{\beta} \tau^{\sigma-1}\right]^{\frac{1-\phi}{\sigma-1}} \vartheta \\
{\left[\frac{\pi_{\alpha}}{\pi_{\alpha}+\delta_{\alpha}}\left[1-\frac{2}{3} N_{\alpha}^{\frac{1}{2}} \bar{a}_{\alpha, e}^{\prime}\right] \frac{\sigma-1}{\sigma} \varpi_{\alpha}+\frac{\delta_{\alpha}}{\pi_{\alpha}+\delta_{\alpha}}\left[1-\frac{2}{3} N_{\alpha}^{\frac{1}{2}} \bar{a}_{\alpha, u}^{\prime}\right] b_{\alpha}\right] .}
\end{gathered}
$$

The corresponding expression for $\beta$-type cities readily follows:

$$
\begin{gathered}
\left(\frac{p_{\beta}}{p_{\alpha}}\right)^{\phi}\left[m_{\alpha} n_{\alpha} \tau^{\sigma-1}\right]^{\frac{\phi}{\sigma-1}}\left[m_{\beta} n_{\beta}\right]^{\frac{1-\phi}{\sigma-1}} \vartheta \\
{\left[\frac{\pi_{\beta}}{\pi_{\beta}+\delta_{\beta}}\left[1-\frac{2}{3} N_{\beta}^{\frac{1}{2}} \bar{a}_{\beta e}\right] \frac{\sigma-1}{\sigma} \varpi_{\beta}+\frac{\delta_{\beta}}{\pi_{\beta}+\delta_{\beta}}\left[1-\frac{2}{3} N_{\alpha}^{\frac{1}{2}} \bar{a}_{\beta, u}\right] b_{\beta}\right] .}
\end{gathered}
$$

The equilibrium terms of trade are given by (53), and the ranges of intermediates $\left(m_{\alpha}, m_{\beta}\right)$ are given by $(51)$ and $(17)$, all in terms of equilibrium labor market tightness given by (41). 


\subsubsection{Beveridge Curves}

As an exercise, we can confirm that the definition of the city-level Beveridge curve is consistent with equilibrium. In an $\alpha$ - city, the ratio of vacancies to the number of unemployed is defined as

$$
\frac{m_{\alpha} V_{\alpha}}{\frac{\delta_{\alpha}}{\delta_{\alpha}+\pi_{\alpha}} \bar{H}_{\alpha, e}}
$$

Since $V_{\alpha}=\delta_{\alpha} h_{\alpha} / q\left(\theta_{\alpha}\right)$, and by using the labor market equilibrium condition (47), it follows that the ratio of the stock of vacancies to the stock of the unemployed is equal to labor market tightness, $\theta_{\alpha}$.

\subsection{City Size Considerations}

Changes in individual city sizes affect equilibrium real income in each city directly through city geography and through equilibrium labor market tightness, which determines employment and unemployment rates. If a particular city offers greater utility than other cities, within a system of cities, would experience in-migration; if it offers less, it would experience out-migration. In this fashion, we may define equilibrium city size, as the population for which the quantity

$$
\frac{\pi_{j} \frac{\sigma-1}{\sigma} \varpi_{j}+\delta_{j} b_{j}}{\pi_{j}+\delta_{j}}-\frac{2}{3} N_{j}^{\frac{1}{2}}\left[\frac{\pi_{j} \frac{\sigma-1}{\sigma} \varpi_{j} a_{j e}+\delta_{j} a_{j u} b_{j}}{\pi_{j}+\delta_{j}}\right], j=\alpha, \beta,
$$

is maximized for either city type, given the terms of trade. In this optimization, the terms of trade, and the ranges of intermediates (which enter in the first line of (55) and (56), respectively) are taken as given.

The last term within brackets in (57) above increases with labor market tightness $\theta_{\alpha}$, provided that $\frac{\sigma-1}{\sigma} \varpi_{j} a_{j e}>\delta_{j} a_{j u} b_{j}$. Since the range of varieties $m_{\alpha}$ increases with labor market tightness, an increase in labor market tightness $\theta_{\alpha}$ increases expected permanent income in an $\alpha$-type city, given the terms of trade. Given the terms of trade, as city size varies, a tradeoff emerges that is familiar from the system-of-cities literature.

What happens if the terms of trade adjust? Not surprisingly, other things being equal each type of city benefits from improvements in its own terms of trade. But as I discuss above, an increase in city size increases the own terms of trade through the effect on labor market tightness. By substituting in the above equation from Equ. (13) for the terms of trade, the part of the expression for real permanent income in type- $\alpha$, type- $\beta$ cities that accounts for the effects of prices is clarified, respectively for the two types of cities, as follows:

$$
\phi_{\alpha}\left(\frac{z_{\beta}}{z_{\alpha}}\right)^{1-\phi}\left[m_{\alpha} n_{\alpha}\right]^{\frac{\phi}{\sigma-1}-(1-\phi)} m_{\beta}^{(1-\phi) \frac{\sigma}{\sigma-1}} n_{\beta}^{(1-\phi) \frac{\sigma}{\sigma-1}}
$$




$$
\phi_{\beta}\left(\frac{z_{\alpha}}{z_{\beta}}\right)^{\phi} m_{\alpha}^{\phi \frac{\sigma}{\sigma-1}} n_{\alpha}^{\phi \frac{\sigma}{\sigma-1}}\left[m_{\beta} n_{\beta}\right]^{\frac{1-\phi}{\sigma-1}-\phi} .
$$

Returning to examining the impact of changes in exogenous variables, I note the following. An increase in a city's net labor supply increases the range of intermediate varieties of the type it is specializing in. From the definition of the vacancy rate, it also increases labor market tightness. From (21), this reduces the output of each intermediate. Thus, the second and the third term in the first row of (55) above increase with the respective city size. The effect on the terms in the second and the fourth row, for $\alpha$ - type cities, and correspondingly on the third and the fourth row, for $\beta$ - type cities, express the tradeoff between congestion and the increase in employment prospects that a greater labor force brings about. Unfortunately, the underlying tradeoffs involve all parameters of the model, including the relationship between the share of $\alpha$ - varieties in the production of final output and the elasticity of substitution, $\phi$ and $\sigma$. Since the outputs of varieties are functions of labor market tightness in the respective types of cities and their ranges are functions of labor market tightness and of city sizes, the terms of trade are fully determined given the numbers and sizes of both types of cities. Therefore, given city sizes, the conditions for national labor market equilibrium determine the numbers of cities. Alternatively, given the number of cities, the populations of agents with different skills distributed themselves across cities.

\section{Technology Shocks as Business Cycle Effects}

It is convenient to think of the impact of business cycle shocks through the impact on production and individuals' welfare of changes in the productivity parameters. However, it is also interesting to examine the effects of technological improvements to other key features of the model, such as shocks to the matching mechanism, $M(.,$.$) , and other aspects of the$ job matching process, the intracity commuting costs, $\left(\bar{a}_{j, e}, \bar{a}_{j, u}\right)$, and to the intercity shipping costs, $\tau$. Commuting costs affect both time available for work and the cost of job search.

\subsection{The Effects of Labor Productivity}

The productivity parameters in the production of intermediates are $\left(\varpi_{j}, \kappa_{j}\right), j=\alpha, \beta$. I take up first shocks to productivity in the form of decreasing marginal labor requirement, $\varpi_{j}$. I consider first a decrease in $\varpi_{\alpha}$, that affects all $\alpha$ industries in a single $\alpha$-type city. Next I consider a positive aggregate shock to $\varpi_{\alpha}$ affecting all $\alpha$ cities, but not $\beta$-type cities. An increase in $\varpi_{\alpha}$ in a particular city is complicated to analyze, because of free entry, unless I assume that it affects all firms producing $\alpha$-varieties. From (21) and (22), an increase in 
$\varpi_{\alpha}$ has direct positive effects on the equilibrium quantities of output and employment for each variety. Via the job creation and wage setting conditions (41), such a change also leads to an increase of labor market tightness, which is in turn associated with higher employment and lower unemployment rates. However, this makes it harder for firms to hire and therefore at the steady state, from Equ. (21) and (22), this implies lower employment and output for each variety, cet. par.. By using (41) in (21), the resulting expression for $z_{\alpha}$ is an increasing function of $\varpi_{\alpha}$ and of $\theta_{\alpha}{ }^{25}$ It turns out that the net effect on output and employment for each variety is positive. From (47) a positive productivity shock leads to a greater range of varieties. Therefore, for given terms of trade, the effect on permanent income in an $-\alpha$ type of a positive productivity shock is positive.

Such a change may be traced along the Beveridge curve for the particular city. Recall section 4.3, where a changing labor market tightness produces an downward-sloping curve in $(u, v)$ space. An increase in $\varpi_{\alpha}$, cet. par., from (4.3) increases the vacancy rate and reduces the unemployment rate, thus shifting the Beveridge curve for each variety-producing firm by making it more vertical. The Beveridge curve is identical across all $\alpha$-variety producing firms as well as for the specialized city. This follows readily because the unemployment rate is the same across all $\alpha$-variety producing firms; and, in defining the vacancy rate in (4.3), the number of firms $m_{\alpha}$ multiplies both numerator and denominator in (4.3).

Considering the Beveridge curve for all cities specializing in $\alpha$-varieties, one may think of it as a spectrum of curves, or as an "average" of the respective curves. Alternatively, one may obtain the aggregate unemployment and express it in terms of the respective labor forces, on one hand, and vacancies as a share of vacancies and employment across all cities, on the other. At a first level of approximation, since the $\alpha$-variety producing cities have the same sizes, the labor forces are the same. So, the aggregate unemployment rate is the average unemployment rate across the respective cities. However, labor market tightness, and thus unemployment and vacancies in each city is determined by the realization of $\varpi_{\alpha}$.

The effects of changes in parameters on the terms of trade is readily obtained from (54) through the effects on equilibrium labor market tightness. E.g., a productivity improvement in the production of $\alpha$ varieties in the form of an increase in $\varpi_{\alpha}$ leads to an increase in the term of trade of type- $\alpha$ cities (and, similarly, for $\beta$-cities). The net effect of symmetrical productivity improvements on the terms of trade depends on the sizes of the the two types of cities. 


\subsection{The Productivity of Matching}

Consider first the impact of an increase in total factor productivity of the matching function. We write

$$
M(U, V) \equiv \bar{M} \mu(U, V),
$$

where $\bar{M}$ denotes total factor productivity in matching. From (41) by total differentiation we have that ${ }^{26}$ :

$$
\frac{d \theta_{\alpha}}{d \bar{M}}>(<) 0, \text { iff: } \theta_{\alpha}>(<) \frac{(1-\vartheta) \delta_{\alpha}}{\left(\delta_{\alpha}+\rho\right) \gamma} .
$$

In other words, an improvement of the matching process has a positive effect if labor market tightness exceeds a certain threshold.

It is interesting to relax another aspect of the matching process in our context, that is, to assume that unemployed workers do not need to travel to the CBD in order to search for jobs. I return to this below. In that case, returning to Equ. (41), we note that provided that unit commuting costs are greater for employed than for unemployed individuals the labor market would be tighter in larger cities and the unemployment rate would be lower. A decrease in the unit commuting costs that is greater for unemployed individuals, as by their not being required to commute as frequently, than for employed ones brings about an increase in labor market tightness.

\subsection{The Rate of Job Destruction}

The rate of job destruction, which is assumed to be exogenous in this paper, varies across industries. The impact of higher value of the rate of job destruction readily follows from differentiating (41). We find ${ }^{27}$ that

$$
\frac{d \theta_{\alpha}}{d \delta_{\alpha}}<(>) 0, \text { iff } \theta_{\alpha}>(<) \frac{1-\vartheta}{\gamma} .
$$

That is, when the cost of vacancies is sufficiently high relative to the weight of firms in bargaining then firms find it disadvantageous to keep up with opening up vacancies and labor market tightness is lower, the employment rate is lower and the unemployment rate is higher. Cities specializing in industries that are more prone to job destruction, say manufacturing, would experience higher steady state unemployment than those specializing in services.

\subsection{Remarks on Diversified Cities}

It is interesting to compare two alternative urban structures for an economy, one that consist of specialized cities with another that consists of diversified cities. It is possible to obtain the 
counterparts of wage-setting equations and characterize the determination of labor market tightness. Not surprisingly, labor market tightness in the two industries they are jointly determined when the respective industries coexist. The (internal) terms of trade are independent of the number of cities and depend only on the skill composition of the population of each city. An interesting property if the unique solution readily follows. The equilibrium value for $\frac{W_{\alpha, c}}{p_{\alpha}}$ in fact exceeds what would have been its value, cet. par., in the case of specialized cities, $\vartheta \frac{\sigma-1}{\sigma} \varpi_{\alpha}-(1-\vartheta) \frac{\delta_{\alpha}}{\pi_{\alpha}} b_{\alpha}$. The equilibrium value for $\frac{W_{\beta, c}}{p_{\beta}}$ falls short of what would have been its value, cet. par., in the case of specialized cities, $\vartheta \frac{\sigma-1}{\sigma} \varpi_{\beta}-(1-\vartheta) \frac{\delta_{\beta}}{\pi_{\beta}} b_{\beta}$. It is clear from that the bargaining solution compensates workers for the added disutility when other types coexist in the same city. This is reflected in the solution for equilibrium utility.

Diversified cities thus modeled would not confer, cet. par., a special advantage to coexistence residents of different types of skills. Congestion could make them inferior to specialized ones, from the expected utility viewpoint. One possibility for an individual with high skills to be better off in a diversified city relative to a city of her own type, would be due to the terms of trade. The number of cities of different types are relevant for welfare outcomes in diversified cities only in so far as they determine welfare outcomes in specialized cities at spatial equilibrium. Reallocation of workers of any skill type out of diversified cities to newly created specialized cities decreases the own terms of trade and therefore of expected utility as well, and thus has a stabilizing effect on such flows. Under parameter values for which skilled workers live nearer the city center, it is unskilled workers who suffer more from congestion associated with a larger city size.

A way to enhance the attractiveness of living in a diversified city is to assume that unskilled workers may experience improvement of their skills through social learning over time [Glaeser (1999)]. As I show in section 3.1 above, it is analytically quite straightforward to incorporate such a feature into the Bellman equations (25-24) for unskilled types at the steady state, in which case expected utility also depends on the probability per unit of time that an unskilled individual becomes skilled. This is expressed by adding an additional term on the r.h.s. of the Bellman equations, which is equal to the expected capital gain from such a transition. The Bellman equations may then be solved simultaneously for the two types of individuals. It follows that because of continuous skill upgrading of unskilled workers, the relative proportion of individuals of the two skill types would be different in diversified cities at the steady state than in the part of the economy that consists of specialized cities. Another advantage of diversified cities is in the form of savings in shipping costs for intermediates. Such costs moderate the value of variety in production functions, when intermediate varieties are traded across cities. Shipping costs are not incurred when intermediates of both types are produced in the same city. For diversified cities to coexist with specialized cities, saving 
in shipping costs must be sufficiently strong to overcome congestion.

\section{Referrals versus Centralized Job Matching, Loca- tion Decisions and Spatial Structure}

Formal and informal methods of search coexist even in our modern economy. How do such options impact urban equilibrium and urban spatial structure? The paper examines next first the case of individuals' receiving referrals ${ }^{28}$ from others who are dispersed around the urban area and then the case of individuals' receiving tips from their social contacts. In the former case, individuals incur cost to visit others and interact with them; in the latter, individuals benefit by merely being associated with others.

\subsection{Referrals from Dispersed Contacts versus Centralized Job Matching}

So far all job matching takes place at the CBD and requires individuals to travel to the CBD in order to work and to be matched. Next I allow individuals to choose ${ }^{29}$ for job-matching purposes, between traveling to the $\mathrm{CBD}$ and traveling to interact with others within their milieu. In the simplest possible case, where the cost of interaction is incurred in terms of travel costs, then for an individual who is located at $\ell, 0<\ell<\bar{\ell}$, the economic benefit of unemployment per unit of time is given by

$$
b p_{j}\left(1-\tau \int_{-\bar{\ell}}^{\bar{\ell}}|s-\ell| d s\right)=b p_{j}\left(1-\frac{\tau}{2}\left((\ell)^{2}+(\bar{\ell}-\ell)^{2}\right)\right) .
$$

In this case, traveling to the CBD dominates engaging in direct social interactions. However, it is interesting to express more precisely how social interactions influence the job contact rate. I assume that individuals may also be matched with vacancies via referrals by their social contacts, who are located throughout the urban area. ${ }^{30}$

I consider an unemployed individual who is in direct contact with $k$ other individuals. The probability that any of her contacts is employed and hears of a vacancy is $(1-u) \frac{V}{U} u=$ $(1-u) \theta u$. The probability that the individual finds a job thanks to one of her direct contacts ${ }^{31}$

is $(1-u) \theta u \frac{1-(1-u)^{k}}{u} \frac{1}{k}$. The probability of finding a job through through referral by her social contacts is thus:

$$
\operatorname{Prob}_{\mathrm{ref}}(u, \theta ; k)=1-\left[1-(1-u) \theta \frac{1-(1-u)^{k}}{k}\right]^{k}
$$


If $k$ is large, the RHS in (60) is approximated ${ }^{32}$ by

$$
\theta u(1-u) k
$$

The probability of finding a job though a referral from a friend is multiplicative in the total number of people contacted and in the labor market tightness, and in a quadratic function of the unemployment rate. Since labor market tightness is defined as $\theta=\frac{v}{u}$, the approximation in (61) implies that high unemployment rate implies a lower probability that social contacts are employed and thus less likely to pass on a job opening tip.

Unemployed individuals choose how many others to contact so as to maximize the value of unemployment. Recall that individuals consume a unit of housing each, that is density is equal to 1 . If an individual who is located at $\ell$ contacts others within an interval $\left[\ell^{\prime}, \ell^{\prime \prime}\right]$, the probability of finding a job through through all those contacts is equal to: Prob ref $=$ $\theta u(1-u)\left(\ell^{\prime \prime}-\ell^{\prime}\right)$. The RHS of the counterpart of Equ. (24) now becomes:

$$
p_{j} b\left(1-\frac{\tau}{2}\left(\left(\ell^{\prime \prime}-\ell\right)^{2}+\left(\ell^{\prime}-\ell\right)^{2}\right)\right)+\left(\ell^{\prime \prime}-\ell^{\prime}\right) \theta u(1-u)\left[\Omega_{e}(\ell)-\Omega_{u}(\ell)\right]+\bar{R}-R(\ell) .
$$

Maximizing the resulting expression for $\Omega_{u}$ with respect to $\left(\ell^{\prime}, \ell^{\prime \prime}\right)$, the bounds defining the range of social interaction, $\ell^{\prime}, \ell^{\prime \prime}$, yields:

$$
\ell^{\prime}=\ell-\frac{1}{p_{j} b \tau} \theta u(1-u)\left[\Omega_{e}(\ell)-\Omega_{u}(\ell)\right] ; \ell^{\prime \prime}=\ell+\frac{1}{p_{j} b \tau} \theta u(1-u)\left[\Omega_{e}(\ell)-\Omega_{u}(\ell)\right] .
$$

Therefore, the range of locations where it pays to rely on social contacts is equal to $\frac{2}{b \tau} \theta u(1-$ $u)\left[\Omega_{e}(\ell)-\Omega_{u}(\ell)\right]$, and thus depends on $\ell$ implicitly via $\Omega_{e}(\ell)-\Omega_{u}(\ell)$. The solution for the asset values of unemployment and employment require that the choice between job matching at the CBD versus via referral by social contacts be incorporated into the Bellman equations. That is,

$$
\begin{gathered}
r \Omega_{i u}(\ell)=\max \left\{b p_{j}\left(1-\bar{\alpha}_{u} \ell\right)+\theta q(\theta)\left[\Omega_{i e}(\ell)-\Omega_{i u}(\ell)\right]+\bar{R}-R(\ell),\right. \\
\left.b p_{j}+\frac{1}{b \tau}(\theta u(1-u))^{2}\left[\Omega_{i e}(\ell)-\Omega_{i u}(\ell)\right]^{2}+\bar{R}-R(\ell)\right\} .
\end{gathered}
$$

The equilibrium asset values $\left(\Omega_{i e}(\ell), \Omega_{i u}(\ell)\right)$ are obtained as the solutions to the system of simultaneous functional equations (25) and (63). This requires that the conditional present values of lifetime income must be recomputed, and this produces two sets of expressions, one corresponding to CBD matching versus referral matching, respectively, for each of these quantities. However, solving for $\Omega_{i u}(\ell)$ in the case of referral leads to a a second-degree quadratic equation, both of whose solutions are feasible, in principle, but unwieldy. These expressions do not show explicit dependence on $\ell$, but do depend on $\bar{R}-R(\ell)$. By comparing over urban space, one can establish their consistency and show that CBD matching is 
preferable by those located within the interval $\left[0, \ell_{\text {ref }}\right]$, where $\ell_{\text {ref }}$ corresponds to the value that equalizes the two terms in the RHS of (63), when the asset values assume their optimal solutions. This approach is not pursued further here.

Allowing for dispersed location of firms in the presence of labor turnover would likely lead to results similar to those of Zenou (2009a), pp. 286-297. That is, firms would cluster in a zone around the endogenously determined CBD and workers would locate around them. In his model, however, individuals change locations when their labor market status changes, with unemployed workers locating further away from the CBD than employed workers. In contrast, in the main model that I introduce in section ?? and develop further here, individuals locate permanently in urban space. To differential location with respect to labor market status in Zenou, there corresponds here differential location with respect to method of job matching, CBD versus referral-based matching. Although it appears mathematically tedious to close the model, it is conceptually straightforward to think about its implications. At the spatial equilibrium, both methods of job matching would coexist, in principle. Still, it is possible that configurations of parameter values might make either method dominate the other.

\subsection{Referrals from Social Contacts versus Centralized Job Match- ing}

I simplify the referral model by assuming that an individual located at $\ell$ faces an exclusive choice between centralized matching at the CBD and referral matching from social contacts, without having to incur costs in order to interact physically with others. That is, if he chooses matching via social contacts, he does not have to travel to the CBD nor to meet others, and he receives the full unemployment rate per unit of time, $b p_{j}$, when unemployed. I adapt the above Bellman equations by defining an individual's expected value of unemployment as the maximum of CBD matching versus referral matching:

$$
\begin{gathered}
r \Omega_{j u}(\ell)=\max \left\{b_{j} p_{j}\left(1-\bar{\alpha}_{u} \ell\right)+\pi(\theta)\left[\Omega_{j e}(\ell)-\Omega_{j u}(\ell)\right]+\bar{R}-R(\ell),\right. \\
\left.b_{j} p_{j}+u_{j}\left(1-u_{j}\right) \theta E[k]\left[\Omega_{j e}(\ell)-\Omega_{i u}(\ell)\right]+\bar{R}-R(\ell)\right\} .
\end{gathered}
$$

For those locations where referral is preferred in either specialized city type, the steady state unemployment rate is, by using for the job finding probability the approximate version of (60) for large $k$, given by:

$$
u_{j}=\frac{\delta_{j}}{\theta_{j} u_{j}\left(1-u_{j}\right) E[k]+\delta_{j}} .
$$


Noting that Eq. (65) is cubic in $u_{j}$, allows us to solve explicitly ${ }^{33}$ for the unemployment rate:

$$
u_{\alpha, \mathrm{ref}}=\left(\frac{\delta_{\alpha}}{\theta_{\alpha} E[k]}\right)^{\frac{1}{2}}
$$

It is the counterpart here of (??). It is decreasing in labor market tightness, just as in the original case of Eq. (26), and in the expected number of contacts each individual has. Obviously, this solution is acceptable provided that

$$
\frac{\delta_{\alpha}}{E[k]}<\theta_{\alpha}
$$

The rate of job destruction and the average number of contacts define a lower bound on labor market tightness.

I invoke the logic of the definition of the matching function, section 31, to define the rate at which vacancies make contacts with workers as:

$$
q_{\mathrm{ref}}\left(\theta_{\alpha}\right)=\frac{1}{\theta_{\alpha}} \text { Prob }_{\mathrm{ref}}=\left(\frac{\delta_{\alpha}}{\theta_{\alpha} E[k]}\right)^{\frac{1}{2}}\left[1-\left(\frac{\delta_{\alpha}}{\theta_{\alpha} E[k]}\right)^{\frac{1}{2}}\right] E[k]
$$

Under the feasibility condition $(67), q_{\text {ref }}\left(\theta_{\alpha}\right)$ decreases with $\theta_{\alpha}$, which agrees with the respective property of the matching model. It is social contacts that hear of vacancies and pass on the word to individuals.

Expected utility in the case of referrals from social contacts thus becomes:

$$
r \omega_{j, \text { ref }}=\frac{\theta_{j} u_{j}\left(1-u_{j}\right) E[k]}{\theta_{j} u_{j}\left(1-u_{j}\right) E[k]+\delta_{j}} W_{j, \text { ref }}\left(1-\bar{\alpha}_{e} \ell\right)+\frac{\delta_{j}}{\theta_{j} u_{j}\left(1-u_{j}\right) E[k]+\delta_{j}} b p_{j}+\bar{R}-R(\ell) .
$$

I exploit the aspatial nature of referral matching by assuming that parameter values are such that make it dominate CBD matching. When this assumption is not appropriate, coexistence of CBD matching and referral matching may be handled by means of the mixed city model.

Allowing for the fact that unemployment pay in the definition of expected utility (29) for those relying on referrals from social contacts does not depend on distance from the CBD yields:

$$
\mathcal{D}_{j} \equiv \frac{\theta_{j} u_{j}\left(1-u_{j}\right) E[k]}{\theta_{j} u_{j}\left(1-u_{j}\right) E[k]+\delta_{j}} W_{j} \bar{\alpha}_{e}
$$

the wage setting model in an $\alpha$-type specialized city yields:

$$
W_{\alpha, \text { ref }}=\vartheta \frac{\sigma-1}{\sigma} \varpi_{\alpha} p_{\alpha}-(1-\vartheta) \frac{\delta_{\alpha}}{\theta_{\alpha} u_{\alpha}\left(1-u_{\alpha}\right) E[k]} \frac{1}{1-\frac{2}{3} N_{\alpha}^{\frac{1}{2}} a_{e, \alpha}} b p_{\alpha} .
$$

The associated expression for expected nominal income per period in a type- $\alpha$ city is:

$$
\vartheta \frac{\theta_{\alpha} u_{\alpha}\left(1-u_{\alpha}\right) E[k]}{\theta_{\alpha} u_{\alpha}\left(1-u_{\alpha}\right) E[k]+\delta_{\alpha}}\left[1-\frac{2}{3} N_{\alpha}^{\frac{1}{2}} a_{e, \alpha}\right] \frac{\sigma-1}{\sigma} \varpi_{\alpha} p_{\alpha}+\vartheta \frac{\delta_{\alpha}}{\theta_{\alpha} u_{\alpha}\left(1-u_{\alpha}\right) E[k]+\delta_{\alpha}} b p_{\alpha},
$$


and similarly for a type- $\beta$ city. Labor market tightness satisfies the counterpart of (41):

$$
\frac{\gamma}{q_{\mathrm{ref}}\left(\theta_{\alpha}\right)}=\frac{1}{\delta_{\alpha}+\rho}(1-\vartheta)\left[\frac{\sigma-1}{\sigma} \varpi_{\alpha}+\frac{\delta_{\alpha}}{\theta_{\alpha} u_{\alpha}\left(1-u_{\alpha}\right) E[k]} \frac{1}{1-\frac{2}{3} N_{\alpha}^{\frac{1}{2}} a_{e, \alpha}} b_{\alpha}\right],
$$

where $q_{\text {ref }}$, the rate at which firms generate hires per vacancy is now defined by (68) above and is a decreasing function of labor market tightness. Equilibrium labor market tightness and unemployment rate satisfies the system of (65)-(72). In view of the explicit solution for the unemployment rate (66), the right hand side of (72) is decreasing in labor market tightness, and a unique solution exists, which shares the basic properties with model with CBD matching above. In view of this explicit solution for unemployment, (72) becomes

$$
\frac{\gamma}{q_{\mathrm{ref}}\left(\theta_{\alpha}\right)}=\frac{1}{\delta_{\alpha}+\rho}(1-\vartheta)\left[\frac{\sigma-1}{\sigma} \varpi_{\alpha}+\frac{\left(\frac{\delta_{\alpha}}{\theta_{\alpha} E[k]}\right)^{\frac{1}{2}}}{1-\left(\frac{\delta_{\alpha}}{\theta_{\alpha} E[k]}\right)^{\frac{1}{2}}} \frac{1}{1-\frac{2}{3} N_{\alpha}^{\frac{1}{2}} a_{e, \alpha}} b_{\alpha}\right],
$$

It follows that the right hand side of (72) is decreasing in $\theta_{\alpha}$, and under the feasibility condition, the implied rate at which firms generate hires per vacancy, $q_{\text {ref }}\left(\theta_{\alpha}\right)$, decreases with $\theta_{\alpha}$, and a unique equilibrium value of labor market tightness exists. A higher value of expected number of contacts shifts down the right hand side of (72) and thus brings about a lower value of unemployment, provided that the net effect on $\theta E[k]$ is positive. This requires that an assumption be made about the sensitivity of $\operatorname{ref} q\left(\theta_{\alpha}\right)$ with respect to $\theta_{\alpha}$. The solution for $\theta_{\alpha}$ from (73) has the form:

$$
\begin{aligned}
& \theta_{\alpha}=\Theta_{\mathrm{ref}}\left(N_{\alpha}, E[k] ; \varpi_{\alpha}, b_{\alpha}, \delta_{\alpha}\right) \text {. } \\
& (+) \quad(-) \quad(+) \quad(+) \quad(?)
\end{aligned}
$$

In addition to the determinants of $\Theta(\cdot)$ in $(42), \Theta_{\text {ref }}(\cdot),(74)$ also includes the expected number of contacts per person, $E[k]$.

In describing social connections so far, I assumed that individuals of the same type have an equal (average) number of connections with others. Suppose next that individuals' connectedness with others varies in a deterministic fashion across the population. For example, we could assume that social connectedness is described by means of a symmetric socio-matrix, or an adjacency matrix. Each row of this matrix gives the pattern of connectedness with others. That is, if $a_{i^{\prime}, i^{\prime \prime}}=1$, individuals $i^{\prime}$ and $i^{\prime \prime}$ are interconnected. How would different individuals locate? Would they segregate across different cities of the same type, or would they all locate in each city type? These are interesting questions may be pursued further. 


\section{Mismatch and the Planner's Optimum}

I define next the social planner's problem of allocating the economy's resources, while respecting the informational structure ${ }^{34}$ of the economy, in order maximize discounted income per person. The planner's optimum defines the socially optimal level of unemployment and thus allows us to assess the extent of mismatch associated with the operation of a market economy in this setting. Specifically, given a total population of each type of skilled labor, $\left(\bar{N}_{\alpha}, \bar{N}_{\beta}\right)$, the planner's problem is to choose the number of cities of each types, $\left(n_{\alpha}, n_{\beta}\right)$ and their respective populations, $\left(N_{\alpha}, N_{\beta}\right)$, subject to (45), the range of intermediates produced in each city type, $\left(m_{\alpha}, m_{\beta}\right)$, their respective quantities, $\left(z_{\alpha, n}, z_{\beta, n}\right)$, and the quantities of each to be used in each city type, $\left(z_{\alpha, \alpha}, z_{\alpha, \beta} ; z_{\beta, \alpha}, z_{\beta, \beta}\right)$, and the labor market tightness in each city, $\left(\theta_{\alpha}, \theta_{\beta}\right)$, so as to maximize total discounted average real per person in the entire economy at the steady state. Such an aggregation is appropriate because total income is defined in terms of the final good that is locally consumed. Writing expected income per person per unit of time in each city type as output per person in each city type, Exp $\operatorname{Inc}_{j}=\frac{Y_{j}}{N_{j}}$, we have:

$$
\frac{n_{\alpha} N_{\alpha}}{\bar{N}} \times \frac{Y_{\alpha}}{N_{\alpha}}+\frac{n_{\beta} N_{\beta}}{\bar{N}} \times \frac{Y_{\beta}}{N_{\beta}}=\frac{1}{\bar{N}}\left[n_{\alpha} Y_{\alpha}+n_{\beta} Y_{\beta}\right]
$$

where $\left(Y_{\alpha}, Y_{\beta}\right)$ are given by (2), (2), respectively. Decomposing the problem of maximizing the present value of this quantity, subject to appropriate resource constraints, applied at the steady state, we note that the use of intermediates, $\left(z_{\alpha, \alpha}, z_{\beta, \alpha} ; z_{\alpha, \beta}, z_{\beta, \beta}\right)$, is a static problem. Thus, maximization of total income per unit of time with respect to intermediate use and subject to iceberg shipping costs satisfy the resource constraints

$$
\tilde{n}_{\alpha} z_{\alpha, \alpha}+n_{\beta} \frac{1}{\tau} z_{\alpha, \beta}=z_{\alpha, n}, n_{\alpha} \frac{1}{\tau} z_{\beta, \alpha}+\tilde{n}_{\beta} z_{\beta, \beta}=z_{\beta, n}
$$

where $z_{j, n}$ denotes the quantity of intermediate of type $j$, net of its producer's search costs, ${ }^{35}$ $z_{j, n}=z_{j}-\gamma V_{j}$, and yields:

$$
\begin{aligned}
& z_{\alpha, \alpha}=\frac{1}{\tilde{n}_{\alpha}+\tau^{\sigma-1} n_{\beta}} z_{\alpha, n}, z_{\alpha, \beta}=\frac{\tau^{\sigma}}{\tilde{n}_{\alpha}+\tau^{\sigma-1} n_{\beta}} z_{\alpha, n} \\
& z_{\beta, \alpha}=\frac{\tau^{\sigma}}{n_{\alpha} \tau^{\sigma-1}+\tilde{n}_{\beta}} z_{\beta, n}, z_{\beta, \beta}=\frac{1}{n_{\alpha} \tau^{\sigma-1}+\tilde{n}_{\beta}} z_{\beta, n} .
\end{aligned}
$$

The range of intermediates is obtained by (47), and is equal to the respective expected city labor supply divided by expected employment in producing each intermediate: $m_{j}=$ $\frac{1}{h_{j, p}} \frac{\pi_{j}}{\pi_{j}+\delta_{j}} \bar{H}_{j e}$. From the current value Hamiltonian, by expressing the first-order conditions and solving at the steady state, we have the counterparts of (17) and (22) for the planner, 
$\left(z_{j, p}, h_{j, p}\right)$ :

$$
\begin{gathered}
z_{j, p}=\varpi_{j} \kappa_{j} \frac{\sigma-1-\sigma \frac{\gamma \rho}{\varpi_{j} q_{j}\left(\theta_{j}\right)}+\frac{\gamma\left(\rho+\delta_{j}\right)}{\varpi_{j} q_{j}\left(\theta_{j}\right)}}{1+\sigma \frac{\gamma \rho}{\varpi_{j} q_{j}\left(\theta_{j}\right)}-\frac{\gamma\left(\rho+\delta_{j}\right)}{\varpi_{j} q_{j}\left(\theta_{j}\right)}}, j=\alpha, \beta ; \\
h_{j, p}=\frac{\sigma \kappa_{j}}{1+\sigma \frac{\rho \gamma}{q\left(\theta_{j}\right) \varpi_{j}}-\frac{\gamma\left(\rho+\delta_{j}\right)}{\varpi_{j} q_{j}\left(\theta_{j}\right)}}, j=\alpha, \beta .
\end{gathered}
$$

By using the expression for the stock of vacancies at the steady state, $V_{j}=\frac{\delta_{j} h_{j}}{q_{j}}$, we obtain a simplified expression for the quantities of intermediates net of search costs, $z_{j}-\gamma V_{j}$ :

$$
z_{j, n}=z_{j}-\gamma V_{j}=(\sigma-1) \kappa_{j} \varpi_{j} \frac{1-\frac{\gamma\left(\rho+\delta_{j}\right)}{\varpi_{j} q_{j}}}{1+\sigma \frac{\rho \gamma}{q\left(\theta_{j}\right) \varpi_{j}}-\frac{\gamma\left(\rho+\delta_{j}\right)}{\varpi_{j} q_{j}}}, j=\alpha, \beta
$$

By comparing with the expressions for equilibrium output and employment, given by (21) and (22), it follows that social optimum requires greater quantities of both, for the same value of labor market tightness. That reflects the fact that the planner internalizes the search externality affecting producers of intermediates.

By dividing expected employment in each city, $\frac{\pi_{j}}{\pi_{j}+\delta_{j}} H_{j e}, j=\alpha, \beta$, where $\bar{H}_{j e}$, are given by (46), by employment required for each intermediate variety, (78), we obtain expressions for the range of intermediates. Thus, we may rewrite the planner's maximand as follows:

$$
\frac{\left(1-\frac{\gamma\left(\rho+\delta_{\alpha}\right)}{\varpi_{\alpha} q_{\alpha}}\right)^{\phi}}{\left(1+\sigma \frac{\gamma \rho}{\varpi_{\alpha} q_{\alpha}}-\frac{\gamma\left(\rho+\delta_{\alpha}\right)}{\varpi_{\alpha} q_{\alpha}}\right)^{-\frac{\phi}{\sigma-1}}} \frac{\left(1-\frac{\gamma\left(\rho+\delta_{\beta}\right)}{\varpi_{\beta} q_{\beta}}\right)^{1-\phi}}{\left(1+\sigma \frac{\gamma \rho}{\varpi_{\beta} q_{\beta}}-\frac{\gamma\left(\rho+\delta_{\beta}\right)}{\varpi_{\beta} q_{\beta}}\right)^{-\frac{1-\phi}{\sigma-1}}}\left(\frac{\pi_{\alpha}}{\pi_{\alpha}+\delta_{\alpha}}\right)^{\phi \frac{\sigma}{\sigma-1}}\left(\frac{\pi_{\beta}}{\pi_{\beta}+\delta_{\beta}}\right)^{(1-\phi) \frac{\sigma}{\sigma-1}} \mathcal{N}
$$

where $\mathcal{N} \equiv \mathcal{N}\left(n_{\alpha}, n_{\beta} ; N_{\alpha}, N_{\alpha}\right)$, a function of the numbers of city types and their sizes, is defined as

$$
\mathcal{N} \equiv \varpi^{*} \frac{n_{\alpha} \tau^{\sigma(1-\phi)} \tilde{n}_{\alpha}^{\phi \frac{\sigma}{\sigma-1}} n_{\beta}^{(1-\phi) \frac{\sigma}{\sigma-1}}+\tau^{\sigma \phi} n_{\beta}\left(n_{\alpha}\right)^{\phi \frac{\sigma}{\sigma-1}} \tilde{n}_{\beta}^{(1-\phi) \frac{\sigma}{\sigma-1}}}{\left(\tilde{n}_{\alpha}+\tau^{\sigma-1} n_{\beta}\right)^{\phi \frac{\sigma}{\sigma-1}}\left(n_{\alpha} \tau^{\sigma-1}+n_{\beta}\right)^{(1-\phi) \frac{\sigma}{\sigma-1}}} \bar{H}_{\alpha \frac{\sigma}{\sigma-1}} \bar{H}_{\beta e}^{(1-\phi) \frac{\sigma}{\sigma-1}}
$$

and the number of cities adjusted for shipping costs, $\left(\tilde{n}_{\alpha}, \tilde{n}_{\beta}\right)$, are given in $(12)$, and $\varpi^{*}$ is defined as a function of preference, aggregate production function and production of intermediates parameters:

$$
\varpi^{*} \equiv(\sigma-1) \sigma^{-\frac{\sigma}{\sigma-1}} \varpi_{\alpha}^{\phi} \kappa_{\alpha}^{-\frac{\phi}{\sigma-1}} \varpi_{\beta}^{1-\phi} \kappa_{\beta}^{-\frac{1-\phi}{\sigma-1}}
$$

The tradeoffs addressed by the planner's optimum handle the several types of inefficiencies in this paper. One is the pecuniary one associated with the monopolistic competition model: a greater variety of intermediates improves welfare, but requires larger cities; larger cities involve greater congestion. A third is the potential inefficiency of search. Such a formulation of the planner's problem respects the informational structure of the economy, and 
thus obviates the problem of multiplicity that is inherent in the essential decentralization of urban production (due to the lack of ability of agents to coordinate and locate in a particular city), and lends itself to formulations that where individual city characteristics differ. Therefore, the planner's optimum provides the best possible outcome given any set of values of underlying parameters.

We note that the planner's choice of labor market tightness is independent of city size, unlike the case at equilibrium, Eq. (41). Setting labor market tightness optimally involves trading off higher probability of employment - the greater the tightness the greater the probability of employment and the greater variety of intermediates, against greater search costs incurred by firms. That is, the planner's optimum level of employment for each intermediate, given by (78), decreases with labor market tightness, which means more intermediates can be produced, but the quantities of intermediates available for production decrease with labor market tightness. In our formulation of the planner's problem, these tradeoffs determine labor market tightness separably for each type of intermediate. This is also true in the equilibrium case, which of course reflects the counterpart of the job creation condition in the DMP model.

The tradeoffs associated with the numbers of sizes of cities are characterized by the properties of the function $\mathcal{N}\left(n_{\alpha}, n_{\beta} ; N_{\alpha}, N_{\alpha}\right)$, and are thus separable from the determination of labor market tightness and thus socially optimum unemployment. Here, intercity shipping costs are crucial in determining the tradeoff. Very small cities have little congestion, allow for greater variety of intermediates but impose greater shipping costs. Suppose that there are intercity shipping costs, that is, $\tau=1$. The variable part in the right hand side of $(81)$ becomes:

$$
\frac{N_{\alpha}^{\frac{1}{\sigma-1}} N_{\beta}^{\frac{1}{\sigma-1}}}{\left(\bar{N}_{\alpha} N_{\beta}+\bar{N}_{\beta} N_{\alpha}\right)^{\frac{1}{\sigma-1}}}\left(1-\frac{2}{3} a_{\alpha, e} N_{\alpha}^{\frac{1}{2}}\right)^{\phi \frac{\sigma}{\sigma-1}}\left(1-\frac{2}{3} a_{\beta, e} N_{\beta}^{\frac{1}{2}}\right)^{(1-\phi) \frac{\sigma}{\sigma-1}}
$$

Maximizing this quantity with respect to $\left(N_{\alpha}, N_{\beta}\right)$ gives the socially optimal city sizes. The first-order conditions have the form of a system of algebraic equations in $\left(N_{\alpha}, N_{\beta}\right)$ whose solutions may be characterized easily and depend on parameters $\sigma, \phi, a_{\alpha, e}, a_{\beta, e}$ and the total number of skilled labor of the two types, $\bar{N}_{\alpha}, \bar{N}_{\beta}$. It can be shown that the system of equations admits two sets of solutions, one of which is stable and the other unstable. The presence of shipping costs complicates this tradeoff, but it can shown that the planner's optimum city sizes exist. Specifically, planner's optimum city sizes are independent of labor market tightness and thus in general would differ from equilibrium city sizes, defined in section 4.5 above as the city sizes that maximize the quantity in (57). Thus, mismatch arises generically in this model. The planner's optimum and equilibrium sizes coincide only by chance. 
The solution to the planner's problem is predicated on values of shocks to productivity $\left(\varpi_{\alpha}, \varpi_{\beta}\right)$. As they vary, and possibly co-vary, one may trace the path of the vacancy and unemployment rates, the Beveridge curves for the two kinds of cities. Or, one may parameterize how commuting costs differ (reflecting internal geography) across different sites, how shipping costs differ between the $\alpha$ and $\beta$ varieties (where one can be services and the other manufactured goods), and assume an arbitrary distribution of populations across sites, that is cities, and site-specific amenities to study the impact on the tradeoff between equilibrium unemployment and vacancies from those different factors. Alternatively, the varieties may be interpreted as specialized services produced by different occupations, whose distribution over cities differ. All these extensions should be addressed by future research.

\section{Conclusions}

To the best of my knowledge the DMP model of intercity trade introduced by the present paper is novel. Combining the canonical DMP model of labor markets with frictions with a system-of-cities model of intercity trade goes beyond the model of Ioannides (2013), chapter 7, and thus opens up a rich menu of possibilities. Urban business cycles is a well known but still poorly understood phenomenon, and their empirical understanding is only just starting. In addition to the papers reviewed in the introduction to the paper above, the work of Rappaport (2012) and Proulx (2013) provide notable empirical contributions that examine, respectively, the sources of variation in unemployment across US metro areas, and a firm link of changes in unemployment rates to the growth rate of output at the MSA level. The present paper proposes a coherent and firmly micro-founded theoretical model of urban unemployment in an economy of open, trading cities. The present approach enhances the system-of-cities model by allowing for unemployment and fluctuations in economic activity that may differ systematically across cities in a large economy. It also enhances the DMP model of labor markets with frictions by introducing, in addition, spatial frictions of the sort that characterize urban economies. The model's use of international trade tools confers a central role to labor market tightness, akin to factor intensity. The specific applications whereby location decisions within urban areas are influenced by choice between job referrals by social contacts and centralized job matching are another new feature. The model is cast in terms of expected outcomes, which is in line with the original DMP literature. Equilibrium outcomes generically diverge from the planner's optimum: socially optimal unemployment trades off the probability of employment to search costs of firms independently for each skill type and independently of city size, and social optimal city sizes are independent of labor market tightness considerations but reflect both market size effects and the skill composition 
of the economy. In future research, the model should be cast explicitly in stochastic terms and allow for full dynamics rather than a steady state analysis. Finally, the model also innovates by allowing for hiring via referrals from social contacts to coexist with centralized, city-based job matching. 


\section{Notes}

${ }^{1}$ See subsection 6 below for a decentralized model of job-related contacts.

${ }^{2}$ See also Ioannides (2013), 195-198 for a refinement of the Krugman-Overman-Puga framework.

${ }^{3}$ Only a handful of studies have utilized the GDP by metropolitan area data. Notable among them is Proulx (2013).

${ }^{4}$ See Shimer (2010) for an adaptation of the DMP approach to a DSGE setting.

${ }^{5}$ Hall's remark suggests the possibility that accounting for job market matching can be used to help distinguish between the different roles of city size in facilitating MAR externalities, matching and labor pooling.

${ }^{6}$ In Shimer (2007), the mean unemployment and vacancy rates come from JOLTS December 2000 - April 2006, which by the time of Shimer's writing uses data from a single recession, 2000 and the subsequent expansion. However, since then, JOLTS has a lot more coverage. Unfortunately, JOLTS publishes estimates for the US as a whole, by ownership (private vs. public), by "super-sector" and select sectors (based on the North American Industry Classification System), and by region (four regions, Northeast, South, Midwest and West, only for total non-farm) but not by metropolitan area [http://data.bls.gov:8080/PDQ/outside.jsp?survey=jt]. Prior to the appearance of JOLTS, the only proxy for job openings was Help-Wanted Index. See Abraham (1987) for an early analysis of those data, which were collected by the Conference Board, as proxies for vacancy rates. This data collection is now discontinued, but the entire coverage over $1954-2008$ is available for the 50 largest metropolitan areas. Those data were replaced by the Help-Wanted Online index (HWOL) (which started in May 2005), starting with the December 1, 2008 release, with seasonally adjusted data for the U.S., the 9 Census regions and the 50 States. Seasonally adjusted data for occupations have been have been available beginning with the December 2009 release, as well as not seasonally adjusted data for 52 large metropolitan areas, although the Conference Board does intend to provide them in seasonally adjusted form for those metro areas in the future. Most recently, the Conference Board has released an index based on the universe of online job posting, which is unfortunately prohibitively expensive for individual researchers; see Şahin et al. (2012). Diamond and Blanchard (1989) relied on the Help-Wanted Index as a proxy for vacancies.

${ }^{7}$ See subsection 6 for a decentralized model of job-related contacts.

8 The model borrows ideas from Kraay and Ventura (2007)'s model of the international economy, in order to describe intercity trade in the style of Anas and Xiong (2003) as adapted by Ioannides (2013), Chapter 7, Section 7.8, and where hiring is subject to frictions. Kraay and Ventura (2007) allow for a rich set of possible shocks, including monetary shocks, for which urban/regional aspects are particularly interesting but which are not adopted here. Francis, Owyang and Sekhposyan (2009) and Owyang, Rapach and Wall (2009) link a city's business cycle with its industrial structure.

${ }^{9}$ It is trivial to modify $(2-3)$ in order to express that a city produces both types of varieties, the case of diversified cities.

${ }^{10} \mathrm{An}$ apparent difference in this specification from vom Berge (2011), Eq. (12), is due to the fact that he assumes that search costs, as proportional to the stock of vacancies, constitute a component of labor demand by each variety-producing firms. The counterpart of this feature in my model is in Eq. (18), where I assume that a search cost in terms of the intermediate good itself. I thank Philipp von Berge for clarifying 
correspondence.

${ }^{11}$ In a stochastic environment, it would be interesting to allow, like Kraay and Ventura, op. cit., for the $\beta$-industry technology to be operated by $\alpha$-skill types as well. Kraay and Ventura's assumptions allow naturally for $\alpha$ - industry skills to be compatible with $\beta$ - industry employment. Firms in the $\beta-$ industry face infinitely elastic demand curves and behave competitively setting price equal to marginal cost $p_{\beta}=w_{\beta} \varpi^{-1}$. Such an asymmetry in the price elasticity of product demand across the $\alpha$ - and $\beta$-industries adds richness to their model.

12 The derivative is taken of each of the terms involving $z_{\alpha_{n m}}$ in the original description of the rate of output in (1), of which there exist $m_{\alpha}$, and then and then use symmetry to write the firm order conditions.

$13 \frac{\partial}{\partial V_{\alpha, t}} \mathrm{HAM}=0$, where HAM denotes the current value Hamiltonian,

$$
\begin{aligned}
& \mathrm{HAM}=p_{\alpha, t} z_{\alpha, t}-W_{\alpha, t}\left[\varpi_{\alpha} \kappa_{\alpha}+z_{\alpha, t}\right]-p_{\alpha, t} \gamma V_{\alpha, t}+\lambda\left[\varpi_{\alpha} q\left(\theta_{\alpha, t}\right) V_{\alpha, t}-\delta_{\alpha}\left[\varpi_{\alpha} \kappa_{\alpha}+z_{\alpha, t}\right]\right] . \\
& 14-\frac{\partial}{\partial z_{\alpha, t}} \mathrm{HAM}=\dot{\lambda}-\rho \lambda . \\
& 15-\left[p_{\alpha, t}+\frac{\partial p_{\alpha, t}}{\partial z_{\alpha, t}} z_{\alpha, t}-\varpi_{\alpha}{ }^{-1} W_{\alpha, t}-\delta_{\alpha} \frac{\gamma p_{\alpha, t} \varpi_{\alpha}^{-1}}{q\left(\theta_{\alpha, t}\right)}\right]+\rho \lambda=0 .
\end{aligned}
$$

${ }^{16}$ Rearranging it allows one to express the "real wage" $\frac{W_{\alpha}}{p_{\alpha}}$ as a decreasing function of labor market tightness. "[A]t a lower wage rate, jobs are more profitable and more vacancies are created" [Pissarides (2011), p. 1095]. However, unlike in the original Pissarides framework where the job creation condition follows from free entry of firms in creating vacancies, here it follows from the pricing behavior of firms. Free entry is also imposed here in a dynamic sense (20), which along with the job creation condition leads to an expression for the value of vacancies. See (23) below.

17

$$
\frac{\partial z_{\alpha}}{\partial \theta_{\alpha}}=\frac{\frac{\rho \gamma q^{\prime}\left(\theta_{\alpha}\right) \kappa_{\alpha}}{q^{2}\left(\theta_{\alpha}\right)}}{\left(\frac{1}{\sigma}+\frac{\rho \gamma}{q\left(\theta_{\alpha}\right)} \varpi_{\alpha}\right)^{2}}<0
$$

18

$$
\frac{\partial h_{\alpha}}{\partial \theta_{\alpha}}=\frac{\frac{\rho \gamma q^{\prime}\left(\theta_{\alpha}\right) \varpi_{\alpha} \kappa_{\alpha}}{q^{2}\left(\theta_{\alpha}\right)}}{\left(\frac{1}{\sigma}+\frac{\rho \gamma}{q\left(\theta_{\alpha}\right)} \varpi_{\alpha}\right)^{2}}<0, \quad \frac{\partial h_{\alpha}}{\partial \varpi_{\alpha}}=\frac{\frac{\rho \gamma \varpi_{\alpha} \kappa_{\alpha}}{q\left(\theta_{\alpha}\right)}}{\left(\frac{1}{\sigma}+\frac{\rho \gamma}{q\left(\theta_{\alpha}\right)} \varpi_{\alpha}\right)^{2}}>0
$$

${ }^{19}$ Diamond (1982) assumes that the probability of a match is higher when there are larger numbers of both unemployed workers and vacancies, which corresponds to increasing returns to matching. Helsley and Strange (1990) obtain a source of agglomeration economies rooted in job matching, in that larger labor markets may provide better matches between jobs and workers. Stevens (2007) endogenizes the Pissarides matching function. Petrongolo and Pissarides (2001) provide an excellent overview of the literature that the Pissarides matching function has given rise to. Mortensen (2009) also endogenizes the matching function, along the lines of Shimer (2007)'s formulation and shows that the flow of matches is an increasing and concave function of the number of jobs and workers to be matched, holding the other constant, but exhibits increasing returns to scale (except in the limiting case of large numbers of jobs and workers relative to the number of submarkets, "islands"). The Mortensen solution is particularly interesting because it rests in random matching, with the number of matches in each isolated island being the minimum of the realized number of available jobs and workers that search. The sums of the residuals are the numbers of unemployed workers and vacant jobs. The aggregate matching function that arises is the resulting statistical relationship between average meeting rates 
per island and the aggregate numbers of unmatched workers and jobs per island. The 2010 Nobel Price citation, http://static.nobelprize.org/nobel_prizes/economics/laureates/2010/ecoadv10.pdf and the Prize Lectures by the laureates themselves are the best summary of this literature as of the time of writing. See Diamond (2011), Mortensen (2011) and Pissarides (2011).

${ }^{20}$ For a homogeneous city, say a type $\alpha$-city, $R_{\text {tot }}=\int_{0}^{\bar{\ell}} R_{\alpha}(\ell) 2 \pi \ell d \ell=\frac{1}{3} \pi \mathcal{D}_{\alpha} \bar{\ell}^{3}$, for which $\bar{R}=\frac{1}{3} \pi \mathcal{D}_{\alpha} \bar{\ell}$.

${ }^{21}$ This deviates from Wasmer and Zenou, op. cit. and from the the standard structure of search models, as Chris Pissarides reminds me. My intention is to render the bargaining solution for the wage rate independent of location. In the present model, at the spatial equilibrium it is expected lifetime utility that is equalized across locations within and across cities. Associating the bargaining outcome with the increase of the expected value of employment over unemployment, $\Omega_{e}-\Omega_{u}$, would make it dependent on location. That is, the solution for the bargained wage is:

$$
W_{\alpha}=W_{\alpha}(\ell)=\vartheta \frac{\sigma-1}{\sigma} \varpi_{\alpha} p_{\alpha}\left[1-\bar{a}_{e} \ell\right]+(1-\vartheta) b p_{\alpha}\left[1-\bar{a}_{u} \ell\right] .
$$

Substituting back into the expression for utility renders expected equilibrium utility quadratic in $\ell$. For spatial equilibrium, $R(\ell)$ varies quadratically with $\ell$. This in turn produces an expression for total rents per person that is also quadratic in $\ell$ and yields in turn an expected utility net of redistributed rents that is quadratic in city size. This makes the description of land use in mixed (diversified) cities particularly unwieldy, because the switchover point where land use changes is a solution to a quadratic equation. Specifically, the corresponding expression for expected utility is still is available in closed form:

$$
\bar{R}-R(\ell)+\frac{\delta_{\alpha}}{\delta_{\alpha}+\pi_{\alpha}}\left(1-\bar{a}_{\alpha, u} \ell\right) b_{\alpha} p_{\alpha}+\frac{\pi_{\alpha}}{\delta_{\alpha}+\pi_{\alpha}}\left(1-\bar{a}_{\alpha, e} \ell\right)\left[\vartheta \frac{\sigma-1}{\sigma} \varpi_{\alpha} p_{\alpha}\left(1-\bar{a}_{e} \ell\right)+(1-\vartheta) b p_{\alpha}\left(1-\bar{a}_{u} \ell\right)\right] .
$$

I thank Frédéric Robert-Nicoud for directing my attention to the Stole-Zwiebel bargaining solution [ Stole and Zwiebel (1996) ], which has been adopted (after refinements) for multi-person bargaining settings by some recent applications of the DMP model. See Helpman, Otshkoki and Redding (2008). I think that the Pissarides-based large firm model, as adapted to the urban setting by Wasmer and Zenou is more suitable to my model.

22 This follows from expression the unit cost function that corresponds to (1), the production function for the final good in each city.

$$
B\left(p_{\alpha}(z), p_{\beta}(z)\right)=\left[\int_{0}^{m_{\alpha}} p_{\alpha}(z)^{1-\sigma} d z\right]^{\frac{\phi}{1-\sigma}}\left[\int_{0}^{1} p_{\beta}(z)^{1-\sigma} d z\right]^{\frac{1-\phi}{1-\sigma}}, 0<\phi<1, \sigma>1 .
$$

To this cost function ideal price indices may be defined for the $\alpha$ - and $\beta$ - industries:

$$
P_{\alpha}=\left[\int_{0}^{m_{\alpha}} p_{\alpha}(z)^{1-\sigma} d z\right]^{\frac{1}{1-\sigma}} \text {, and } P_{\beta}=\left[\int_{0}^{1} p_{\beta}(z)^{1-\sigma} d z\right]^{\frac{1}{1-\sigma}} .
$$

${ }^{23}$ See Job Openings and Labor Turnover Survey, p. 5 http://www.bls.gov/web/jolts/jlt_labstatgraphs.pdf

${ }^{24}$ It is easy to incorporate economy-wide trade in the final good, an extension not undertaken here.

${ }^{25}$ By using the definition of the vacancy rate to substitute for $\frac{\gamma}{q\left(\theta_{\alpha}\right)}$ in $(21)$, we have:

$$
z_{\alpha}=\frac{\frac{\sigma-1}{\sigma} \varpi_{\alpha}\left(\delta_{\alpha}+\rho \vartheta\right)-\rho(1-\vartheta) \frac{\delta_{\alpha}}{\pi_{\alpha}}}{\frac{1}{\sigma}\left[\delta_{\alpha}+\rho+\rho(1-\vartheta)(\sigma-1)\right]+\rho(1-\vartheta) \varpi_{\alpha} \frac{\delta_{\alpha}}{\pi_{\alpha}}} \kappa_{\alpha} .
$$


Working similarly with (22), we have:

$$
h_{\alpha}=\frac{1}{\frac{1}{\sigma}\left[\delta_{\alpha}+\rho+\rho(1-\vartheta)(\sigma-1)\right]+\rho(1-\vartheta) \varpi_{\alpha} \frac{\delta_{\alpha}}{\pi_{\alpha}}} \kappa_{\alpha} .
$$

26

$$
\frac{d \theta_{\alpha}}{d \bar{M}}=\frac{\frac{1}{\bar{M}^{2} \mu(U, V)}\left[\gamma \theta_{\alpha}-\frac{1-\vartheta}{\delta_{\alpha}+\rho} \delta_{\alpha}\right]}{\left.\frac{\gamma m_{1}}{\bar{M} \mu^{2}\left(\theta_{\alpha}^{-1}, 1\right) \theta_{\alpha}^{2}}+\frac{(1-\vartheta) \delta_{\alpha} \mu_{2}}{\left(\delta_{\alpha}+\rho\right.}\right) \bar{M} \mu^{2}\left(1, \theta_{\alpha}\right.} .
$$

27

$$
\frac{d \theta_{\alpha}}{d \delta_{\alpha}}=\frac{\frac{1-\vartheta-\theta_{\alpha} \gamma}{\left(\delta_{\alpha}+\rho\right) \pi_{\alpha}}}{-\frac{\gamma q^{\prime}}{q^{2}}+\frac{1-\vartheta}{\delta_{\alpha}+\rho} \frac{\delta_{\alpha}}{\pi^{2}} \pi^{\prime}} .
$$

${ }^{28}$ Galenianos (2014) proposes a model of referral hiring. An equilibrium search model of the labor market is combined with a rudimentary social network. The key features are that the workers' network transmits information about jobs and that wages and firm entry are determined endogenously. The model has no spatial features.

${ }^{29}$ I thank Chris Pissarides for urging me to examine this aspect of the model.

${ }^{30}$ An elegant alternative formulation is Zenou (2009a), p. 286-297, where he also tackles the endogeneity of firms' location, in addition to those by individuals. Instead of assuming that all firms are located in the CBD, Zenou models firms as benefitting from interacting with other firms in the urban economy, and in optimizing their location they take the interaction cost along with their labor and land costs into consideration. By symmetry, the CBD continues to be the geometrical center of the urban economy, but firms locate in a ring around it, followed by employed individuals, and with unemployed ones locating in the outer most ring. Zenou's formulation implies that individuals move when their employment state changes. This sharp prediction may also be modified if relocation costs are assumed. The ensuing model [Zenou (2009b)] predicts that with sufficiently high relocation costs, workers would not relocate with unemployment, which in effect implies the model used by the present paper.

${ }^{31}$ This is derived in detail in Calvó-Armengol and Zenou (2006) and Ioannides and Soetevent (2006). It is consistent with the identifying assumptions of Topa (2001).

${ }^{32}$ First, note that

$$
1-(1-u)^{k} \approx k u
$$

This yields in turn:

$$
\operatorname{Prob}_{\operatorname{ref}}(u, \theta ; k) \approx 1-[1-\theta(1-u) u]^{k} \approx \theta u(1-u) k .
$$

This calculation may also be seen as a simplification of matching model in Galeotti and Merlino (2014), Eq. (3).

An analysis by Calvó-Armengol and Zenou shows that as $k$ varies, the exact probability of $\operatorname{Prob}_{\mathrm{ref}}(u, \theta ; k)$ increases initially until it reaches a unique maximum and decreases thereafter. The economic intuition for this finding is that increasing network size makes coordination failures more likely. Although unemployed workers receive on average more job openings through their social network as social network size increases, information about vacancies may be wasted as it becomes more likely that an unemployed worker receives multiple notifications of the same vacancy. 
${ }^{33}$ Of the three roots, one is equal to 1 , and of the other two, (66) is a feasible solution for unemployment.

${ }^{34}$ I note that by choosing labor market tightness in each city type as decision variables, the planner'a problem respects the informational structure of the economy. This formulation is in agreement with that by Şahin et al. (2012).

35 In expressing the current value Hamiltonian, we recognize that it is the quantities of intermediates net of search costs that are available for production. The current value Hamiltonian may be written as:

$$
\begin{aligned}
& \mathrm{HAM}=\left(n_{\alpha}\left(\tilde{n}_{\alpha}\right)^{\phi \frac{\sigma}{\sigma-1}} n_{\beta}^{(1-\phi) \frac{\sigma}{\sigma-1}}+n_{\beta}\left(n_{\alpha}\right)^{\phi \frac{\sigma}{\sigma-1}} \tilde{n}_{\beta}^{(1-\phi) \frac{\sigma}{\sigma-1}}\right)\left(z_{\alpha}-\gamma V_{\alpha}\right)^{\phi}\left(z_{\beta}-\gamma V_{\beta}\right)^{1-\phi} \\
& \times\left[\kappa \alpha+\varpi_{\alpha}^{-1} z_{\alpha}\right]^{-\phi \frac{\sigma}{\sigma-1}}\left[\kappa_{\beta}+\varpi_{\beta}^{-1} z_{\beta}\right]^{-(1-\phi) \frac{\sigma}{\sigma-1}}\left[\frac{\pi_{\alpha}}{\pi_{\alpha}+\delta_{\alpha}} H_{e, \alpha}\right]^{\phi \frac{\sigma}{\sigma-1}}\left[\frac{\pi_{\beta}}{\pi_{\beta}+\delta_{\beta}} H_{e, \beta}\right]^{1-\phi} .
\end{aligned}
$$

The production constraints, according to (17), are adjoined by:

$$
+\lambda_{\alpha}\left[\varpi_{\alpha} q\left(\theta_{\alpha}\right) V_{\alpha}-\delta_{\alpha}\left(\varpi_{\alpha} \kappa_{\alpha}+z_{\alpha}\right)\right]+\lambda_{\beta}\left[\varpi_{\beta} q\left(\theta_{\beta}\right) V_{\beta}-\delta_{\beta}\left[\varpi_{\beta} \kappa_{\beta}+z_{\beta}\right]\right]
$$

The first order conditions with respect to $V_{\alpha}, V_{\beta}$, yield:

$$
\lambda_{\alpha} \varpi_{\alpha} q\left(\theta_{\alpha}\right)=\gamma \phi \frac{\mathrm{HAM}}{z_{\alpha}-\gamma V_{\alpha}}, \lambda_{\beta} \varpi_{\beta} q\left(\theta_{\beta}\right)=\gamma \phi \frac{\mathrm{HAM}}{z_{\beta}-\gamma V_{\beta}} .
$$

The first order conditions with respect to $\lambda_{\alpha}, \lambda_{\beta}$, yield:

$$
\begin{aligned}
& -\phi \frac{\mathrm{HAM}}{z_{\alpha}-\gamma V_{\alpha}}+\phi \frac{\sigma}{\sigma-1} \frac{\mathrm{HAM}}{\varpi_{\alpha} \kappa_{\alpha}+z_{\alpha}}+\delta_{\alpha} \lambda_{\alpha}=\dot{\lambda_{\alpha}}-\rho \lambda_{\alpha} ; \\
& -\phi \frac{\mathrm{HAM}}{z_{\beta}-\gamma V_{\beta}}+\phi \frac{\sigma}{\sigma-1} \frac{\mathrm{HAM}}{\varpi_{\beta} \kappa_{\beta}+z_{\beta}}+\delta_{\beta} \lambda_{\beta}=\dot{\lambda_{\beta}}-\rho \lambda_{\beta} .
\end{aligned}
$$




\section{REFERENCES}

Anas, Alex, and Kai Xiong, 2003. "Intercity Trade and the Industrial Diversification of Cities," Journal of Urban Economics, 54, 258-276.

Anderson, Fredrik, Simon Burgess, and Julia I. Lane. 2007. "Cities, Matching, and the Productivity Gains of Agglomeration." Journal of Urban Economics 61:112-128.

Bergsman, Joel, Peter Greenston, and Robert Healy. 1972. The Agglomeration Process in Urban Growth," Urban Studies, 9, 3, 263-288.

Black, Duncan, and J. Vernon Henderson 2003. "Urban Evolution in the USA," Journal of Economic Geography, 3, 343-372.

Blanchard, Olivier J., and Peter A. Diamond. 1989. "The Beveridge Curve." Brookings Papers on Economic Activity 1:1-76.

Bleakley, Hoyt, and Jeffrey Lin. 2007. "Thick-Market Effects and Churning in the Labor Market." Evidence from US Cities." Federal Reserve Bank of Philadelphia, working paper No. 07-23, October.

Coulson, N. Edward. 2006. "Measuring and Analyzing Urban Employment Fluctuations," In: Arnott, Richard and Daniel McMillen, editors, Blackwell Companion to Urban Economics.

Cuñat, Alejandro, and Marc J. Melitz. 2012. "Volatility, Labor Market Flexibility, and the Pattern of Comparative Advantage." Journal of the European Economic Association. 10(2):225-254.

Diamond, Peter A. 2011. "Unemployment, Vacancies, Wages." American Economic Review. 101:1045-1072.

Diamond, Charles A. and Curtis J. Simon. 1990. "Industrial Specialization and the Returns to Labor." Journal of Labor Economics 8(2):175-201.

Dixit, Avinash K., and Joseph E. Stiglitz 1977. "Monopolistic Competition and Optimum Product Diversity," American Economic Review 67, 3, 297-308.

Dornbusch, Rudi, Stan Fischer, Paul A. Samuelson. 1977. "Comparative Advantage, Trade, and Payments in a Ricardian Model with a Continuum of Goods." American Economic Review 67(5):823-839. 
Duranton, Gilles and Diego Puga. 2005. "From Sectoral to Functional Urban Specialization." Journal of Urban Economics 57:343-370.

Dutt, Pushan, Devashish Mitra, and Priya Ranjan. 2009. "International Trade and Unemployment: Theory and Cross-National Evidence." Journal of International Economics $78: 32-44$.

Fujita, Masahisa, Paul Krugman, and Anthony Venables. 1999. The Spatial Economy: Cities, Regions, and International Trade, MIT Press.

Galenianos, Manolis. 2014. "Hiring through Referrals." Journal of Economic Theory. 152:304-323.

Galeotti, Andrea, and Luca Paolo Merlino. 2014. "Endogenous Job Contact Networks." International Economic Review. 55(4):1201-1226.

Gan, Li, and Quinghua Zhang. 2006. "The Thick Market Effect on Local Employment Rate Fluctuations." Journal of Econometrics, 133 (1): 127-152.

Gan, Li, and Qi Li. 2004. "Efficiency of Thin and Thick Markets." NBER working paper 10815.

Glaeser Edward L., and Joseph Gyourko. 2005. "Urban Decline and Durable Housing." Journal of Political Economy 113(2):345-375.

Francis, Neville, Michael T. Owyang and Tatevik Sekhposyan. 2009. "The Local Effects of Monetary Policy." St Louis Fed working paper 2009-048A, September.

Helpman, Elhanan, and Oleg Itskhoki. 2010. "Labor Market Rigidities, Trade and Unemployment." The Review of Economic Studies. 77(3):1100-1137.

Helsley, Robert W., and William C. Strange. 1990. "Matching and Agglomeration Economies in a System of Cities." Regional Science and Urban Economics 20(2):189-212.

Henderson, J. Vernon 1974. "The Size and Types of Cities," American Economic Review, $64,4,640-656$.

Henderson, J. Vernon 1987. "Systems of Cities and Inter-City Trade," 71-119, in Hansen, Pierre, Martin Labbé, Dominique Peeters, and Jacques-Francois Thisse, and J. Vernon Henderson, Systems of Cities and Facility Location, 1987. Harwood Academic Publishers, Chur. 
Henderson, J. Vernon 1988. Urban Development: Theory, Fact, Illusion. Oxford University Press, Oxford.

Ioannides, Yannis M. 2013. From Neighborhoods to Nations: The Economics of Social Interactions. Princeton, NJ: Princeton University Press.

Kline, Patrick, and Enrico Moretti. 2013. 2013. "Place Based Policies with Unemployment." American Economic Review. 103(3): 238-243.

Kraay, Aart, and Jaume Ventura. 2007. "Comparative Advantage and the Cross-Section of Business Cycles." Journal of the European Economic Association, 5(6):1300-1333.

Koren, Miklós, ans Silvana Tenreyro. 2007. "Volatility and Development." Quarterly Journal of Economics 122(1):243-287.

Krugman, Paul R. 1991. Geography and Trade. Cambridge, MA: MIT Press.

Lentz, Rasmus, and Dale T. Mortensen. 2012. "Labor Market Friction, Firm Heterogeneity, and Aggregate Employment and Productivity." Working Paper, University of Wisconsin. October.

Mortensen, Dale T. 2009. "Island Matching." Journal of Economic Literature 144:23362353.

Mortensen, Dale T. 2011. "Markets with Search Friction and the DMP Model." American Economic Review 101:1073-1091.

Mortensen, Dale T., and Christopher A. Pissarides. 1999. "New Developments in Models of Search in the Labor Market." In Handbook of Labor Economics. Vol. 3B. Eds. Orley Ashenfelter and David Card. 2567-2627. New York: Elsevier Science.

Overman, Henry G., and Diego Puga. 2010. "Labour Pooling as a Source of Agglomeration: An Empirical Investigation." In Glaeser, Edward L., ed., The Economics of Agglomeration, Chicago, IL.: The University of Chicago Press.

Owyang, Michael T., Jeremy M. Piger, and Howard J. Wall. 2005. "Business Cycle Phases of U.S. States." Review of Economics and Statistics 87: 604-616.

Owyang, Michael T., Jeremy M. Piger, Howard J. Wall, Christopher H. Wheeler. 2008. "The Economic Performance of Cities: A Markov-Switching Approach." Journal of Urban Economics 64(3): 538-550. 
Owyang, Michael T., Jeremy M. Piger, and Howard J. Wall. 2010. "Discordant City Employment Cycles." working paper, Federal Reserve Bank of St. Louis, 2010-019, July.

Owyang, Michael T., David E. Rapach, and Howard J. Wall. 2009. "States and The Business Cycle." Journal of Urban Economics 65:181-194.

Petrongolo, Barbara, and Christopher A. Pissarides. 2001. "Looking into The Black Box: A Survey of the Matching Function." Journal of Economic Literature 39:390-431.

Pissarides, Christopher A. 2000. Equilibrium Unemployment Theory. Cambridge, MA: MIT Press.

Pissarides, Christopher A. 2011. "Equilibrium in the Labor Market with Search Frictions." American Economic Review 101:1192-1205.

Proulx, Kevin B. 2013. "A Spatial Investigation of Urban Labor Markets." MS thesis, Department of Economics, Tufts University.

Rappaport, Jordan. 2012. "Why Does Unemployment Differ Persistently across Metro Area." Economic Review. Federal Reserve Bank of Kansas City, Second Quarter 2012. $5-35$.

Rossi-Hansberg, Esteban and Mark L. J. Wright. 2007. "Urban Structure and Growth." Review of Economic Studies 74:597-624.

Şahin, Ayşegül, Joseph Song, Giorgio Topa, and Giovanni L. Violante. 2012. "Mismatch Unemployment." NBER Working paper 18265. Forthcoming, American Economic Review.

Shimer, Robert. 2007. "Mismatch." American Economic Review. 97(4):1074-1101.

Simon, Curtis J. 1988. "Frictional Unemployment and the Role of Industrial Diversity." The Quarterly Journal of Economics, 103 (4): 715-728.

Simon, Curtis J. 2004. "Industrial Reallocation across US Cities, 1977-1997." Journal of Urban Economics 56:119-143.

Stevens, Margaret. 2007. "New Microfoundations for the Aggregate Matching Function." International Economic Review 48(3):847-868.

Stole, Lars A. and Jeffrey Zwiebel. 1996. "Intra-firm Bargaining under Non-binding Contracts." Review of Economic Studies. 63(3):375-410. 
Tang, Heiwai. 2012. "Labor Market Institutions, Firm-specific Skills, and Trade Patterns." Journal of International Economics. 87(2):337-351.

vom Berge, Philipp. 2011. "A solvable Agglomeration Model with Unemployment." University of Regensburg Working Paper. No. 461.

Zenou, Yves, and Etienne Wasmer. 2006. "Equilibrium Search Unemployment with Explicit Spatial Frictions." Labour Economics 13: 143-165.

Zenou, Yves. 2009a. Urban Labor Economics. Cambridge: Cambridge University Press.

Zenou, Yves. 2009b. "Urban Search Models under High-relocation Costs. Theory and Application to Spatial Mismatch." Labour Economics 16:534-546.

Zenou, Yves, and Etienne Wasmer. 2006. "Equilibrium Search Unemployment with Explicit Spatial Frictions." Labour Economics 13: 143-165.

Zhang, Qinghua. 2005. "Microfoundations of Local Business Cycles," Department of Economics, University of Texas Austin, working paper. December.

Ziesemer, Thomas. 2003. "Information and Communication Technology as Technical Change in Matching and Production." Journal of Economics 79(3): 263-287. 